Article

\title{
Digital Twin and Web-Based Virtual Gaming Technologies for Online Education: A Case of Construction Management and Engineering
}

\author{
Samad M. E. Sepasgozar ${ }^{D}$ \\ Faculty of Built Environment, University of New South Wales Sydney, Sydney 2052, Australia; \\ Sepas@unsw.edu.au or samad.sepasgozar@gmail.com
}

Received: 8 June 2020; Accepted: 3 July 2020; Published: 7 July 2020

\begin{abstract}
Mixed reality is advancing exponentially in some innovative industries, including manufacturing and aerospace. However, advanced applications of these technologies in architecture, engineering, and construction (AEC) businesses remain nascent. While it is in demand, the use of these technologies in developing the AEC digital pedagogy and for improving professional competence have received little attention. This paper presents a set of five novel digital technologies utilising virtual and augmented reality and digital twin, which adds value to the literature by showing their usefulness in the delivery of construction courses. The project involved designing, developing, and implementing a construction augmented reality (AR), including Piling AR (PAR) and a virtual tunnel boring machine (VTBM) module. The PAR is a smartphone module that presents different elements of a building structure, the footing system, and required equipment for footing construction. VTBM is developed as a multiplayer and avatar-included module for experiencing mechanisms of a tunnel boring machine. The novelty of this project is that it developed innovative immersive construction modules, practices of implementing digital pedagogy, and presenting the capacity of virtual technologies for education. This paper is also highly valuable to educators since it shows how a set of simple to complex technologies can be used for teaching various courses from a distance, either in emergencies such as corona virus disease (COVID-19) or as a part of regular teaching. This paper is a step forward to designing future practices full of virtual education appropriate to the new generation of digitally savvy students.
\end{abstract}

Keywords: virtual reality; augmented reality; digital twin; 360 modules; YouTube; online App; construction; building; digital pedagogy; role play; e-learning; risk management

\section{Introduction}

Visiting a real construction site is not always possible due to site restrictions, the limited number of students permitted to enter a site, and, more recently, due to COVID-19. Virtual modules can be used for online education in architecture, engineering, and construction (AEC). They can also be applied to formative learning, flipped classroom [1], blended experimental teaching [2], and online teaching modes [3]. Previous studies investigated the feasibility of using virtual technology in education in different contexts, such as healthcare [4]. Recent studies intend to use virtual technology for education in construction and architecture such as Bashabsheh et al. [5], Wang et al. [6], Eiris Pereira and Gheisari [7], and Gao et al. [8]. However, the application of virtual technologies to show real physical practices in an immersive environment without using headsets for AEC education purposes has not been thoroughly investigated. There are complicated processes in construction, such as drilling and boring underground, which students have not experienced before, and traditional learning methods such as textbooks cannot easily deliver the knowledge. In contrast to text-based learning materials, 
there is a possibility of practicing in a simulated environment that allows students for correction and repetition to improve their skills with non-risk failures [9]. The purpose of this study is to present novel tools and online virtual applications to present the complicated processes of drilling, piling, and boring and an excavator digital twin to AEC students. The digital twin refers to the digital replica of a physical entity utilising the internet of things enabling two-way communications between them. The excavator digital twin and other education apps also address the deficiencies of traditional approaches in terms of promoting the engaging capabilities that allow students to be fully immersed in virtual space $[6,10,11]$. The purpose of these virtual apps is to enable large scale site visits, that will enable students to enter a virtual environment and learn a building case study or heavy equipment. The AEC courses may use project-based learning (PBL) approaches [12], so students are required to enhance their cooperation and collaboration skills [13]. Also, group project learning is recommended to all other educational disciplines at universities [14]. However, several severe challenges of PBL have not been adequately addressed for large classrooms. For example, the way instructors can measure each group member's contribution to their group assignment and give them immediate feedback in large classes will be much more difficult when it comes to the implementation of flipped learning methods or formative learning approaches.

The main research questions are:

(1) How can mixed reality and digital twins be applied in construction education?

(2) What virtual and augmented reality modules can provide a collaborative environment, and what factors may enhance students' engagement in construction education?

(3) What are the key values and advantages of the selected technologies in construction?

\subsection{Significance and Advantages of Virtual Technology}

The significance of virtual technologies is that it helps users to have an active experience rather than a passive learning experience and enhances their creativity $[15,16]$. Emerging technologies and virtual tools have caused a significant change in education methods, including construction education [17]. They shifted education and professional practices significantly away from the traditional individual theory-based lecturing to group PBL, similar to other practical disciplines. Project-based learning refers to learning from a specific construction project as a case study. Examples of group-based learning methods in engineering are problem-solving with open-ended solutions [18,19], hands-on projects [20], and team-oriented communications [21]. More recently, the concept of active learning and student engagement has had a significant impact on education design in practical courses [22], arguing that students learn more and are more prepared for their careers by actively applying the course materials. Some researchers recommended flipped classroom models for construction management $[1,23]$. However, this new highly lauded method has not yet received enough attention in the AEC, including the construction management discipline, particularly for large classrooms $[1,24,25]$. Also, there are not enough digital tools to support this teaching method. The problem is that the educator cannot take a large class of students into a construction site. This is particularly an important problem where a specific activity such as piling is not at the same time as the teaching period.

PBL is recommended to many educational disciplines at universities [14]. The PBL assessment is the core concern of many studies in different fields, including AEC, and students need to work collaboratively and enhance their social and cooperation skills. Table 1 presents the positive and negative experiences of students in doing PBL based on the literature. 
Table 1. Overall advantages, experience, and barriers to group project assessments.

\begin{tabular}{|c|c|c|}
\hline Students Experience & Description & References \\
\hline Overall advantage & Encourage them to be more active and more engaged & Lee, et al. [26] \\
\hline \multirow{3}{*}{ Positive experience } & Reduce their workload and made their assignment more manageable & Finlay and Faulkner [27] \\
\hline & Allow them to cover more materials with group members & Finlay and Faulkner [27] \\
\hline & Their critical thinking skills would be improved through group conversation & Finlay and Faulkner [27] \\
\hline \multirow{3}{*}{ Negative experience } & Conversations were superficial and time-consuming & Bahar-Özvaris, et al. [28]; Herrmann [29] \\
\hline & $\begin{array}{l}\text { The group learning method took away lecture time where "facts" and direct } \\
\text { answers would be provided }\end{array}$ & Lee, Ngampornchai, Trail-Constant, Abril and Srinivasan [26] \\
\hline & $\begin{array}{l}\text { Not productive because it takes time for the group to arrive at conclusions, } \\
\text { mostly no results or consensus would be made }\end{array}$ & Lee, Ngampornchai, Trail-Constant, Abril and Srinivasan [26] \\
\hline \multirow{2}{*}{ Barriers } & Free-riders could be misidentified & Hall and Buzwell [30] \\
\hline & Group members are not equally contributing to their assignment & Hassanien [31]; Hall and Buzwell [30] \\
\hline
\end{tabular}




\subsection{Theoretical Factors}

Virtual education utilizes a set of systems, including hardware and software, that provide an immersive environment or a "sensory illusion" to feel present in a different environment [32]. In virtual education, immersion, learners' perceptions, presence, and interactive activities are known as critical factors. The quality level of these factors, including immersion and interactivity, are related to technological attributes of the utilised technology such as digital images/videos, the display resolution, and other associated gadgets [32]. Lee et al. [33] suggests a set of factors that may increase users' satisfaction of a virtual reality module, including presence, motivation, virtual features, cognitive benefits, usability, reflective thinking. Some factors that are related to the technology acceptance model include usefulness and usability [34-36]. However, some other factors that are related to psychological aspects of learning, such as motivation, may enhance the effectiveness of learning and are usually considered in virtual learning tools. Lee et al. [33] also discuss that the cognitive factors are also important since they enhance understanding and memoriation of the learning subjects in the virtual environment. Memorisation increases the ability of students to recall events, facts, or definitions. Radianti et al. [32] discussed that 'immersion, presence, and interactivity' should be considered in technology design as core characteristics of the virtual module. From a psychological perspective, immersion refers to a state that the student feels isolated from the senses of being in the real world [32].

The literature discusses different factors that can be used for measuring students' experience of using newer technologies and predicting technology acceptance [37,38]. Nakarada-Kordic et al. [39] examined four principal measures of presence, such as feeling 'real', 'relaxed', 'comfortable', and 'anxious', while using the VR, before experiencing magnetic resonance imaging technology in medicine. They found that the VR experience improves participants' experiences before a potentially stressful use of the imaging examination. There are many published papers concerning sickness due to the use of VR applications. Kim et al. [40] developed a motion sickness metric for a successful VR implementation such as discomfort, fatigue, eye strain, difficulty in focus, headache, blurry vision, dizziness, head fullness, and vertigo.

The literature also presents the significance of tools or instructions to help students by enriching learning tasks, activities, and also with relevant experiences [41] (p. 3). However, this might be time-consuming and difficult to help students in large classes. A key component of providing active learning experiences in the classroom is that students need to be prepared for active engagement in the class [42] (p. 369). The flipped classroom is a change in the sequence in which activities are done by which students interact with the course materials [1]. In the flipped classroom, students preview the course materials before class so that they can do a part of their homework and other learning activities in class (workshop) [1]. As explained by Bliemel [43] (p. 113), core lesson materials can be available to students before class, including digital content and short videos. Preparing students before class or supporting them after class one by one is not easily possible in large classes. The purpose of this paper is to offer novel virtual technologies that potentially can be useful for online education and suitable to various class sizes and different teaching philosophies such as flipped classroom, blended learning, role-play learning, formative or summative approaches.

In particular, the current studies also investigate the positive and negative aspects of group project assessment and report that it is not possible to estimate the students' contribution to the main work accurately. However, some other studies provide some strategies to identify free-riders and/or assess other group members' contributions to the group project [44-46]. They offer different methods of peer evaluation or peer-assessments to assist lecturers in identifying the overall contribution of each group member. These methods are mainly based on a simple form asking students to give a mark of 100 to the group members based on their contribution to the group project. This form is an additional source to assess students' contributions to their group projects. However, there is not a reliable tool to detect biases and a valid measure to understand the level of each group member. Therefore, there is a need to address the mentioned problems by developing a novel technology-based model to evaluate group projects' individual marks accurately. 
Learning management systems (LMSs) offer useful online tools for managing large classrooms [37,47]. Still, the current systems do not fully support a mix of educational approaches such as roleplay-based group project. In this paper, a set of tools, including a Group Wiki Project (GWiP) is offered as an essential tool for doing an online group project, as shown in Table 2. The GWiP is one of the necessary tools of Web 2.0 that provides spaces to write by students of the group in a web-based setting. This is a constructive activity and constitutes active learning in which students build an individual representation of their knowledge based on their peers' experiences [48].

Table 2. Characteristics of the collaborative learning platform.

\begin{tabular}{ccc}
\hline Factor & Advantage & References \\
\hline Sharing & $\begin{array}{c}\text { Students can easily share their ideas and give } \\
\text { immediate feedback to each other }\end{array}$ & $\begin{array}{c}\text { Elmahadi and Osman [49]; Sonego, et al. [50], } \\
\text { Gutiérrez-Braojos, et al. [51] }\end{array}$ \\
\hline Collaborate and communicate & $\begin{array}{c}\text { Allow a multi-player option enabling students to } \\
\text { experience immersive, interactive and real-time } \\
\text { meetings and working }\end{array}$ & $\begin{array}{c}\text { Cooper, et al. [52] and Gutiérrez-Braojos, } \\
\text { Montejo-Gamez, Marin-Jimenez and Campaña } \\
\text { [51], Monahan et al. [53], Zheng, et al. [54] }\end{array}$ \\
\hline Quick editing & Students can quickly edit their page & Biasutti and EL-Deghaidy [48] \\
\hline Simple & $\begin{array}{c}\text { The WiKi page is a simple mark-up scheme to set } \\
\text { format (comparing HTML) }\end{array}$ & Dominic, et al. [55] \\
\hline Maintainable & $\begin{array}{c}\text { Easy to link the page to other pages or sources } \\
\text { (e.g., YouTube etc.) }\end{array}$ & Biasutti and EL-Deghaidy [48] \\
\hline Open-source & $\begin{array}{c}\text { Easy to save the database, track all edits, logs and } \\
\text { see the history and manage previous versions }\end{array}$ & Biasutti and EL-Deghaidy [48] \\
\hline Everyone who has access to WiKi can edit it & Dominic, Francis and Pilomenraj [55] \\
\hline
\end{tabular}

Männistö et al. [56] reviewed digital collaborative learning practices in nursing education and found out that this type of learning is beneficial since it contributes to knowledge construction and building on each student's interaction. At the same time, they suggest that instructors should provide more guidance to students and design a suitable pedagogical solution by using an appropriate tool for this type of practice [56]. There is a need to develop virtual tools for allowing the opportunity for collaborative learning or cooperative learning. In a collaborative learning process, students are not only working together to carry out their group projects, but they also need to work actively with their group mates and correct each other. Computer-supported collaborative learning systems should be developed further [57]. This type of collaborative learning is known as socio-constructivist [56]. Blau et al. [58] also discuss that this type of practice improves students' self-regulation skills and their learning proficiency by providing peer feedback while completing their project.

This paper first discusses a case study, including materials that should be taught in a construction subject; second, a variety of learning tools produced for online practice will be reviewed; and finally, an overall evaluation of students' feedback is discussed. Limitations and topics for future studies are also discussed in the discussion section. In this investigation, the forefront of contemporary advancements and innovation in AEC education was used to increase the authenticity of learning by being virtually present on site.

\section{Research Method}

In order to enhance students learning experience and improve virtual education in construction, this paper developed a set of virtual modules and discussed their applicability in construction. A practical construction course was used as a case study, and details of the course are presented [1]. First, a set of virtual modules have developed, as shown in Figure 1. Then, users tested and used them. The developed technologies were tested by a team of experts, including designers, technical programmers, educational developers, and students during the developing process, as well as before finalising the module. When the development process had been completed, a group of volunteer students was interviewed to learn their experience of using a virtual learning module. In order to improve education technologies, a scientific semi-structured interview was conducted among 
construction management students examining their experience and insights gained when using a selected virtual module. The semi-structured interview approach and content analysis are commonly used in the construction context [59-63]. The interviews were analysed manually by using the concept of thematic analysis. Students chosen as users of the modules were also selected to express their experience of using the modules. Their content on GWiP is used as learning evidence. With a focus on the interactive construction reality tour (iCRT) learning experience, the interviews interrogate the potential of the virtual module to support and elevate the students' engagement with the construction process through an immersive or interactive experience. This systematic data collection through interviews allows for a greater understanding of the student perspectives, learning processes, and adoption behaviour [64]. The users' feedback will enhance further development and adoption of VR tools and associated activity-level. Some topics that were asked to be discussed by the interview participants are as follows:

- How did a virtual module help you understand construction operations? For example, did you understand the link between excavators and trucks, piling rigs, and processes?

- If so, give an example of what have you learned or what was interesting to you in the module?

- What was your favourite part of the modules, and why?

- Do you think it made excavation operation process concepts clearer to you? And what subjects do you think complement or help assist in gaining a depth of knowledge?

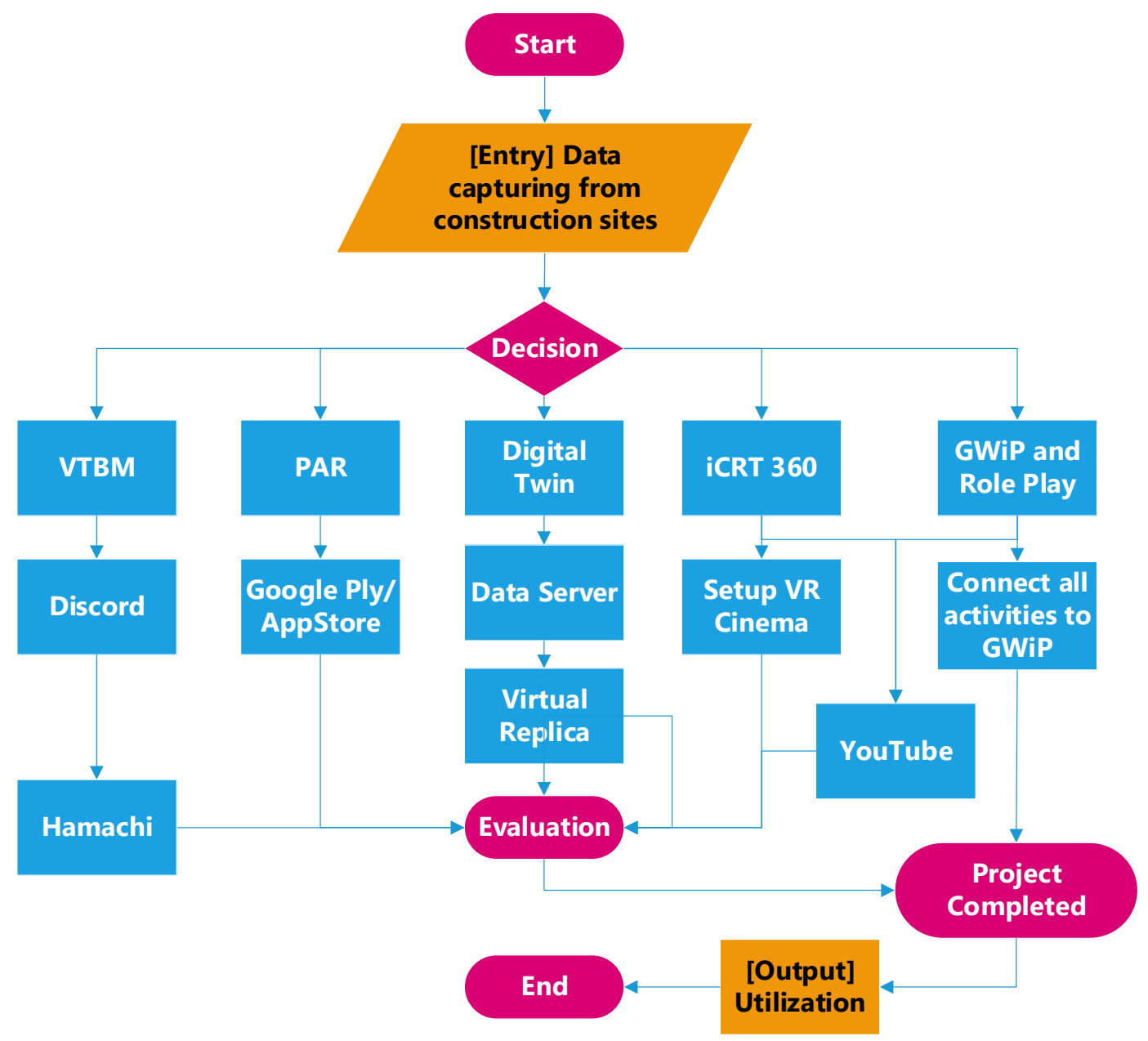

Figure 1. Flowchart of mixed reality modules developed for virtual education, including digital twin and online App. VTBM: Virtual Tunnel Boring Machine, PAR: Pilling Augmented Reality, iCRT: interactive reality tour, GWiP: Group WiKi Project. 
The data collected from ten interviews were analysed in Sections 3 and 4. The students' feedback and their note on GWiP were used for identifying some key factors that may affect virtual technology acceptance.

Figure 1 shows the process, including data collection from construction projects to develop virtual learning modules, including VTBM, PAR, DT, and iCRT. These modules were created for students. GWiP is available on Moodle to students, and a short presentation of their work is available on YouTube. iCRT is available in a cylinder room, namely VR Cinema, and a simplified version is available on YouTube. VTBM is a virtual app that students will be given a link to download the file in conjunction with Discord and Hamachi to use it from home. PAR and DT are available on Google Play or App Store to students so they can download and use it anytime.

This section presents details of the selected courses, including objectives and topics which should be learned by students. The online modules, in this case, were developed to highlight principles that are difficult to recreate for students in the construction and engineering setting. The interactive resources were developed and used for the online delivery of relevant courses in different disciplines. This course was designed and improved by utilising different virtual technologies over five years from the time the course initially was created in 2016. The selected course is called Infrastructure and Industrial Construction (IIC), with the following details:

- First-year large foundational core courses. These students have not seen the entire process of underground activities.

- The course was designed based on collaborative learning and authenticity approaches in which unique virtual and online materials will be helpful;

- $\quad$ Large classes varying from 200 to 300 students, require developing digital materials for increasing the learning experience while being less expensive;

- Cover four learning outcomes to enhance students' ability to understand the processes and mechanisms of a variety of construction activities, as listed in Table 3.

Table 3. Selected course learning outcomes for the chosen course about infrastructure construction.

\begin{tabular}{ccc}
\hline ID & Learning Statement & Related Assessment \& Activities \\
\hline 1 & $\begin{array}{c}\text { Identify and analyse the management requirements, } \\
\text { scopes, mechanisms, operational systems, } \\
\text { performance and outcomes of a variety of } \\
\text { contemporary national and international IIC projects }\end{array}$ & Quiz, Project and Final Exam \\
\hline 2 & $\begin{array}{c}\text { Analyse the construction processes and technologies } \\
\text { used in infrastructure projects }\end{array}$ & Project and Final Exam \\
\hline 3 & $\begin{array}{r}\text { Critically analyse the strategic, tactical and } \\
\text { operational challenges of IIC projects }\end{array}$ & Project \\
\hline 4 & $\begin{array}{c}\text { Demonstrate a range of professional characteristics } \\
\text { required for IIC project personnel }\end{array}$
\end{tabular}

Table 3 shows the learning statements of the IIC course, which is a first-year core course with 300 students. This course was designed to extend students' knowledge of technologies, systems, and processes of industrial and infrastructure construction. This case study practised this approach by providing a portfolio of activities that includes students (i) forming their role playgroups, (ii) interacting with an industry guest lecturer, (iii) using the immersive environment (VR Cinema) to learn tacit knowledge about a construction case study, and (iv) learning from peers in group projects via GWiP. Arranging site visits for all students poses serious logistical challenges in terms of costs and personal safety considerations. These resources can transform the learning experience of students, very much in line with the objectives of the institutional strategies of improving the learning experience and the education literature. Selected topics covered in this course are shown in Table 4. 
Table 4. Selected topics covered in the case chosen course.

\begin{tabular}{cc}
\hline Week & Topic \\
\hline Week 1 & Introduction to construction project organisations \\
\hline Week 2 & Site preparation and estimating earthmoving production \\
\hline Week 3 & Road construction and equipment \\
\hline Week 4 & Productivity, risk identification, and safety in practice \\
\hline Week 5 & Substructure, piling and tunneling construction \\
\hline Week 6 & Logistics, materials handling and mechanisation \\
\hline Week 7 & Trench shoring and temporary structures \\
\hline Week 8 & Superstructure and bridge construction \\
\hline Week 9 & Sustainable infrastructure and demolition technology \\
\hline
\end{tabular}

The GWiP was applied for the Industrial and Infrastructure construction course to give a chance to all students to do their group assignment based on their background and knowledge. The university strategy encourages lecturers to use innovative teaching methods. For a smooth transition between the traditional dominant face-to-face delivery model to the full online classroom model, a combination of different tools was designed and employed, as shown in Figure 1. To increase the authenticity of the modules, a set of engaging industry partners and world-class contractors were involved in the process of developing virtual modules caused in producing useful and valuable sources to students.

\section{Technology Design}

This section presents a set of tools and technologies to address the research questions of how mixed reality and digital twins can be applied in construction education and what virtual and augmented reality modules can provide a collaborative environment. These tools were developed for practical construction courses, as shown in Figure 2. Selected participants and stakeholders who are involved in this project include two leading construction contractors and consultants, the university estate management, the portfolio of the pro-vice-chancellor (education), a few instructors, and students from the Faculty of Built Environment, the Faculty of Engineering, and external technology vendors. Students at different education levels were involved in the project. In particular, two undergraduate students, two master's students, and one PhD student participated in the project of recording videos or preparing content for the VTBM module. These participants were involved in creating interactive teaching resources. These resources can be used in different courses such as construction informatics, digital construction, risk management, and practice-based courses, but were mainly used for designing the IIC pedagogy, so-called BLDG1021. Six novel interactive modules have been developed, as shown in Figure 2, and details are provided as follows.

\subsection{Group Wiki Project and Role Play}

The first module (refer to Figure 2) is an innovative group project online template, namely GWiP, which was designed for students to do their group projects together, where tutors and other instructors could monitor students' work in real-time. There is a lack of online tools available so far to show the students' progress in real-time transparently. In particular, measuring the student's contribution to their group project is always challenging, but the problem has been solved by the GWiP. All tutors and the instructor use GWiP to monitor students' progress weekly, give them relatively quick feedback, and increase the quality of their group project at the global level. Each group then presented their work (as a scenario base/role play based) and uploaded it on YouTube.

GWiP was perceived as useful technology helping students to prepare their group projects. Rogers [65] suggests that usefulness is one of the two critical factors of technology acceptance and can be used as a construct to predict a successful digital technology implementation. The advantage 
of GWiP was perceived as follows: students drafted their project gradually during the semester; instructors, including their tutor and lecturer, monitored their progress during the semester; the 'history' option on GWiP enabled the lecturer to check who contributed the group assignment more than others. GWiP's history page shows the number of words written by everyone with time.

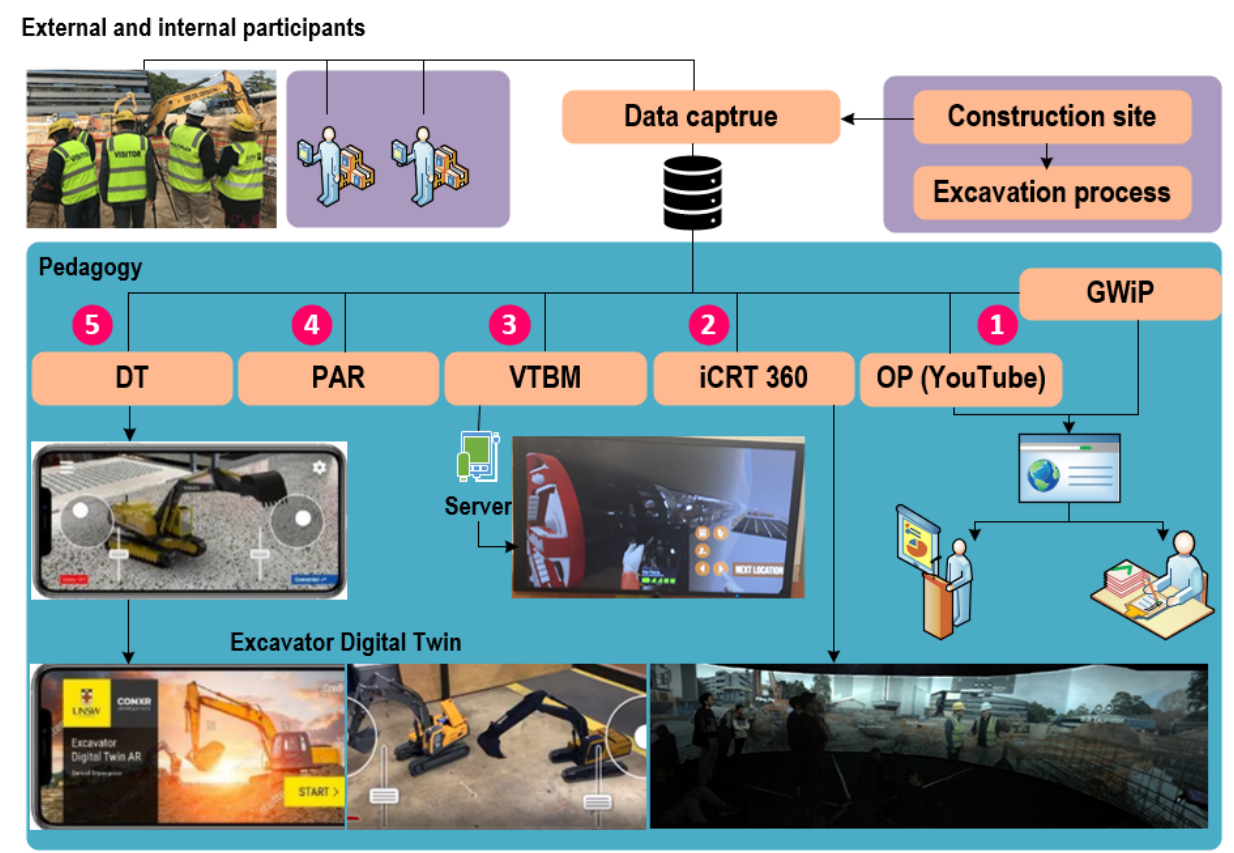

Figure 2. The flowchart of developed online modules, including screenshots of the applications, including Excavator Digital Twin.

GWiP increases the transparency of the teamwork, and students do not need to submit or print their projects at the end of the semester since all information will be saved automatically in their computer. For example, a total of 27 groups were formed by students in one semester. Then, $27 \mathrm{GWiP}$ groups were created on WiKi Moodle by the lecturer each semester. Each student was asked to create a page within his GWiP. The group leaders also were encouraged to add extra WiKi pages for their group: 'executive summary,' 'project description,' and 'sharing ideas.'

The students were required to select and analyse a project (e.g., rail work, tunnel, highway, factory, and bridge) based on the relevant information, which they collected. They also were asked to describe their project (on GWiP) in a way that a person not familiar with the project could obtain a clear understanding of the project. The information was related to the course topics, including construction sites (e.g., location and accessibility), construction processes, project organisations, project monitoring, and their learning processes. Groups were encouraged to use theories and topics from the lecture throughout the semester and address them in their project. Based on GWiP, students were able to start their projects in two hours workshop running following the lecture and continue doing their projects any time per week in an online web-based setting.

Subsequently, each student analysed and discussed their chosen project on an individual online page. In this method, they do not use conventional word files, and instead, they described and reported their project on the GWiP page. The online pages allowed the lecturer and tutors to provide regular feedback on their drafts on GWiP. A page called 'Feedback on your Work' was created for each group, and the lecturer and grading tutors use this page to provide feedback to the students of each group. They were asked to identify features of their role, which presents something exciting, challenging, or unique about their role in their real project. They were provided with an example of people involved in the crane operation process, including crane supervisor, coordinator, operator, signaler, and slinger, as shown in Figure 3. It also shows that each group chose one project, and each individual took a 
specific role as examples of tasks. Figure 3 presents some of the groups and their workshop ID and the map page of their GWiP, their role, names, and ID numbers. In the first step, students take individual roles, then make the required online pages. They assessed the pages and received group and personal feedback on their work. The GWiP gives the possibility to the lecturer to assess students individually online, and at any time, so each individual within the group is assessable.

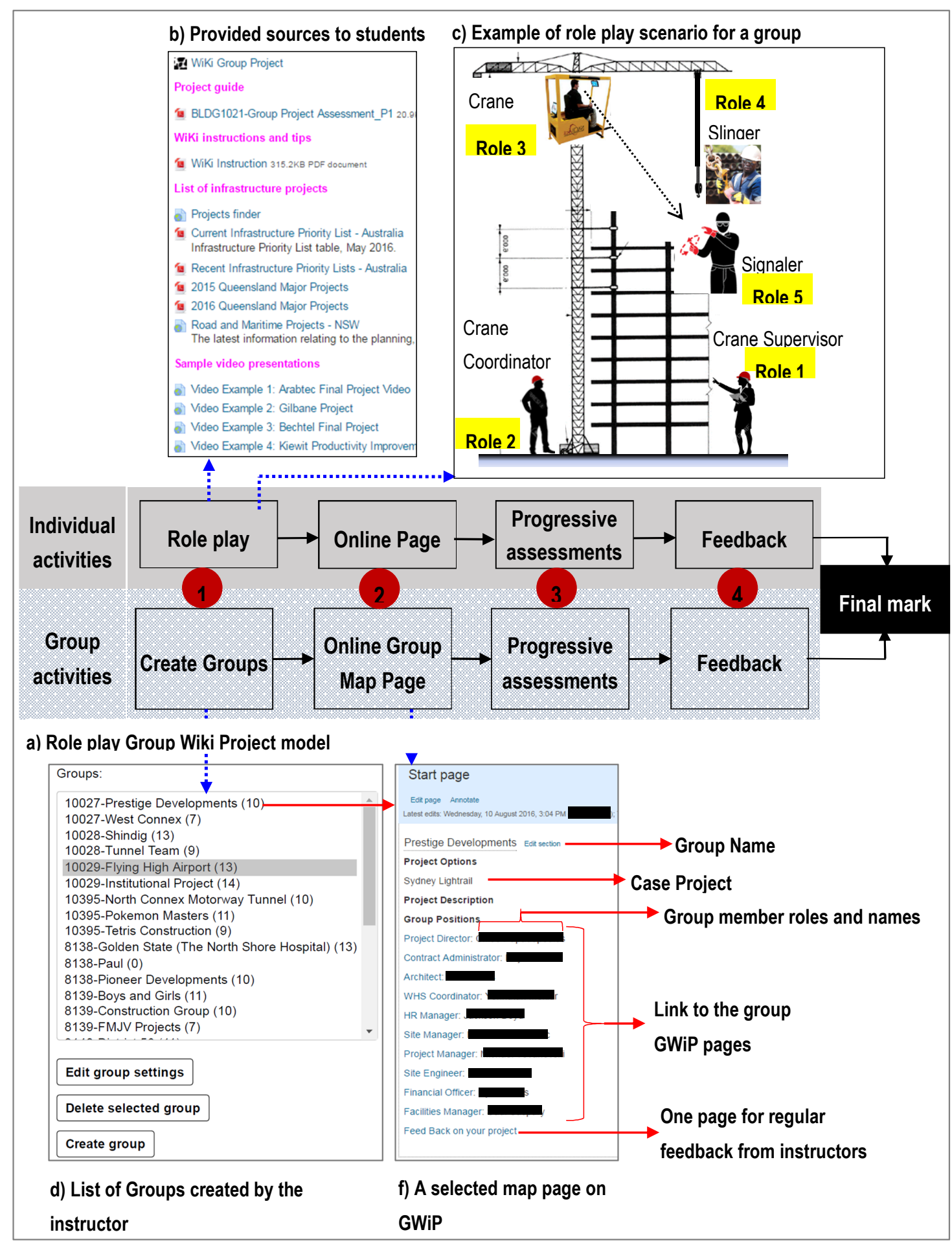

Figure 3. Role playgroup project model and list of groups and examples on GWiP. (a) Role play Group Wiki Project model; (b) Provided sources to students; (c) Example of role play scenario for a group; (d) List of Groups created by the instructor; (f) A selected map page on GWiP. 
Then students presented the entire project in a video format and made it available on YouTube (search BLDG1021). Since the course was a large-sized class of over 200 students, applying to the role-play approach and presentation in class was not efficient, so students were asked to use computer visualisation aids and produce their videos and upload them on YouTube. This method helped the student to present the project they have completed during the term. This is in line with the project-based learning (PBL) approach [13]. The resources made by students are always available and helpful to next semester's students. Examples are shown in Figure 4.

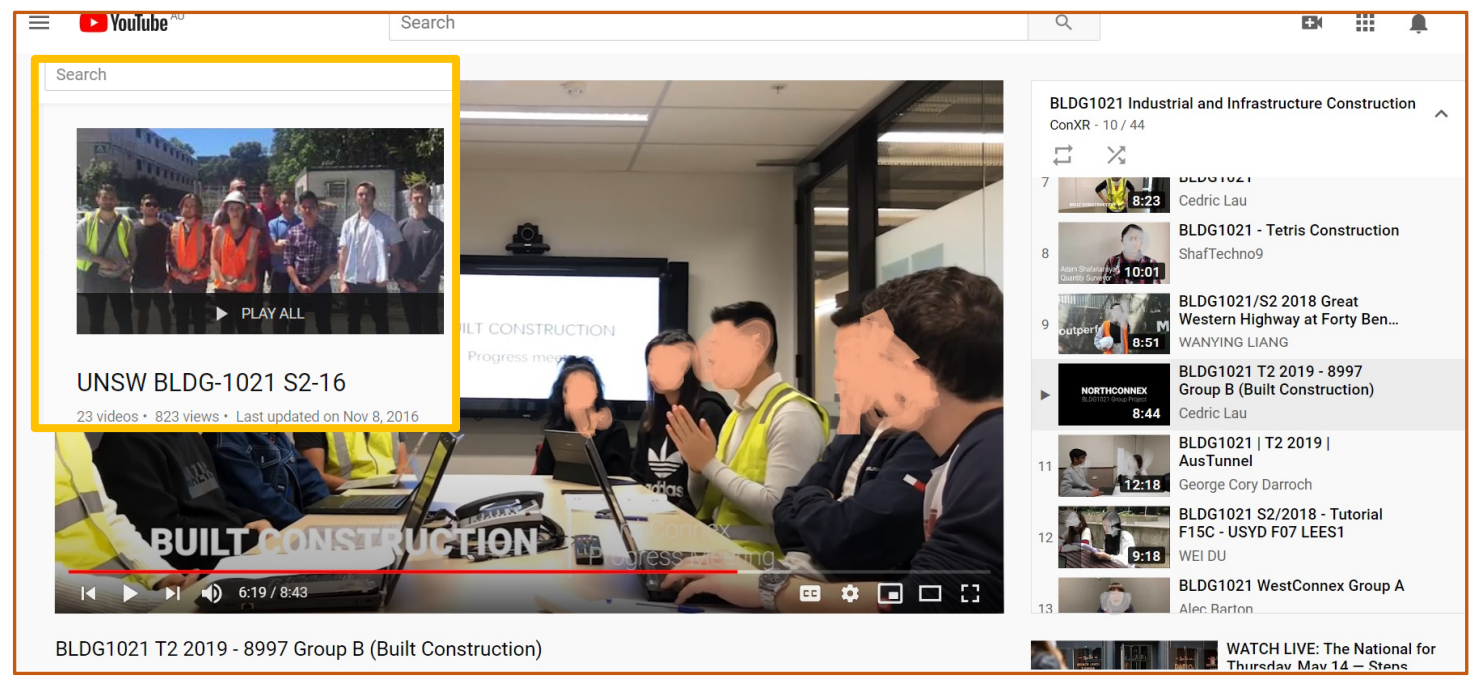

Figure 4. Students' presentations of their role-play practice uploaded on YouTube by themselves.

\subsection{Interactive Construction Tour 360}

The second online module (refer to Figure 2) is called iCRT 360, including videos recorded the real construction site of the Science and Engineering Building as a case study as shown in Figure 5. The content of recorded videos was combined with quizzes and interviews with the contractor (i.e., multiplex) on-site staff. The physical area of the immersive iCRT is a stereoscopic and interactive system. It consists of a cylindrical canvas which five high definition projectors visualise the image onto. These five projectors work collectively in sync allowing the 3-dimensional (3D) visualisation of movement to feel smooth and immersive.
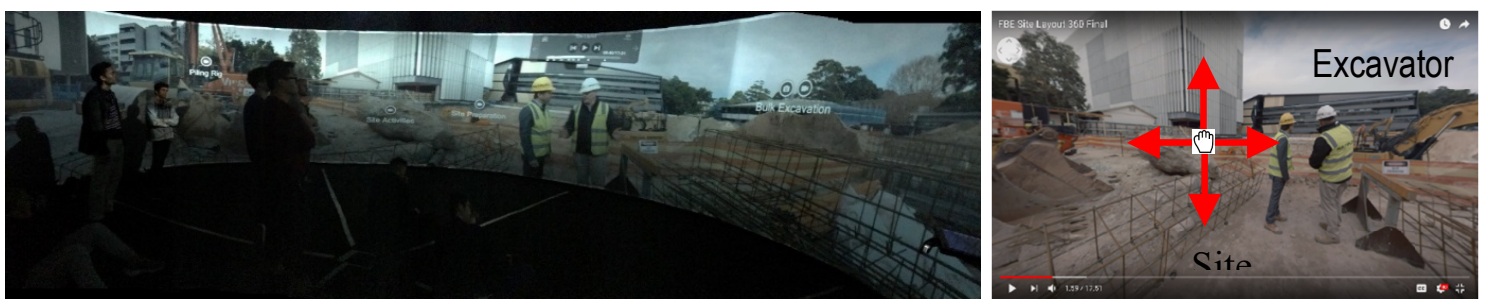

Figure 5. Panning of an iCRT module sample module used for the case course [66,67] (See: https: //www.youtube.com/channel/UCOzhGK8xOdoCc3Y9mJHnAnA/).

Additionally, motion tracking systems and stereo sound in the VR environment allowed students to interact with the projected modules allowing the opportunity for an immersive experience within an interactive VR environment. Added features in this format were the hotspots that detail specific parts of the construction process, including the equipment involved. Hotspots contained both short videos as well as photos to provide a more in-depth explanation of these processes and equipment. This feature allowed a degree of flexibility by varying emphasis on the description of different aspects of a construction site. 
The iCRT uses the current technologies and cameras to capture rich information of complex construction activities for reproducing real practices meaning that students can visit noteworthy events during or any time after the event. The iCRT combines the current experience of Australian projects and the tacit knowledge of practitioners and uniquely involves them in digital education. The iCRT includes several modules covering underground and excavation activities in construction sites, as shown in Figure 6. For example, one of the modules focused on drilling and the pilling process. These activities are not visible, and students cannot see what is happening underground. Underground activities, excavation, and drilling are not safe for students to visit since there are many hazards in the areas these activities take place. Also, the entire process of piling, including excavation, inserting cages, concreting, may not be possible to carry out within visit times. Since these places are not safe, and the timing is also not under control, there is a need to visualise and create more interactive virtual resources to students.
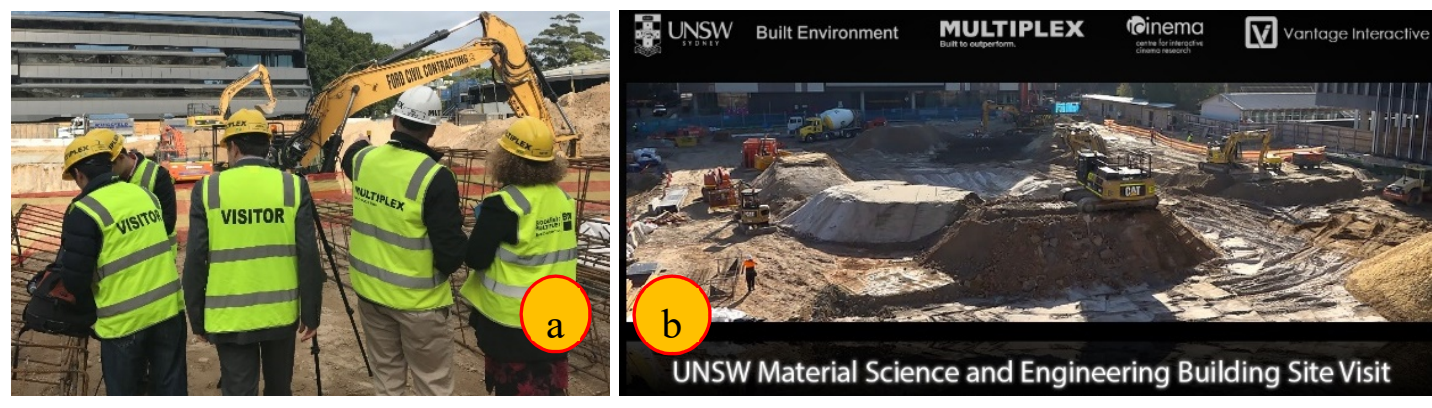

Figure 6. Leading a team of internal and external parties for developing the modules from fieldwork to digital lab production. (a) fieldwork for production planning in 2017; and (b) capturing 360 footages, including some patterns' logo involved in the production.

These resources aim to give the students a virtual experience of significant site and excavation works through cognitive learning in a workplace-based learning environment. Cognitive learning aims to teach learners the processes that experts use to handle complex tasks, situated within the context in which they would usually and naturally be carried out. It also aims to simulate the actual cognitive processes that have to be undertaken for a complicated task to be learned. A construction site, where students can find themselves surrounded by massive earthworks and equipment worth millions of dollars, can now be experienced first-hand through these new digital and virtual technologies, in a cost-effective, secure and efficient manner.

For more accessibility and further exposure (albeit at lower quality), the 360-degree VR videos were uploaded to a video delivery service that supports VR video, on YouTube. Students could view the VR video content through a desktop/mobile web browser, or through the Android/iOS YouTube apps. If students open these links up in Google Chrome, they can see details of the construction site or pilling process by zooming in/out. For example, if a student makes a mouse scroll, the user will get closer or farther away from the target. Students will be able to click and drag with a mouse to look in all directions of the construction site to explore all around the site.

Figures 7 and 8 show that the module is running using a server computer in the room behind the circular room. However, a tutor can control the module, including backward-forward, pushing the hotspots, and changes the modules using a tablet in front of the students. This is so students can become involved in running and managing the process of using the modules in groups of 10 to 20, which depends on the capacity of the cylindrical room as shown in Figure 9.

The virtual developed modules have responded to the disadvantage of digital education by dealing with the practical needs of the course. The virtual modules have the potential to change the students' learning attitude to be virtually present on site and increase the authenticity of learning by its virtual presence on-site and being able to see site managers operating in the modules. The modules allowed students to experience real practice, while savings on resources, transportation, time, and money compared with regular site visits made the virtual modules a much more sustainable proposition. 
It also enabled practitioners to optimise their current processes to save more resources. The student's engagement was enhanced using these virtual modules, including iCRT, in the immersive environment. The simple version of my resources can also be used online remotely, which is precisely in-line with the UNSW 2025 Strategic Plan recommending the utilisation of "blended learning products with seamless integration of the physical and digital campuses". These products are critical for enhancing students' learning in construction since construction equipment is costly and project sites are often difficult to access.
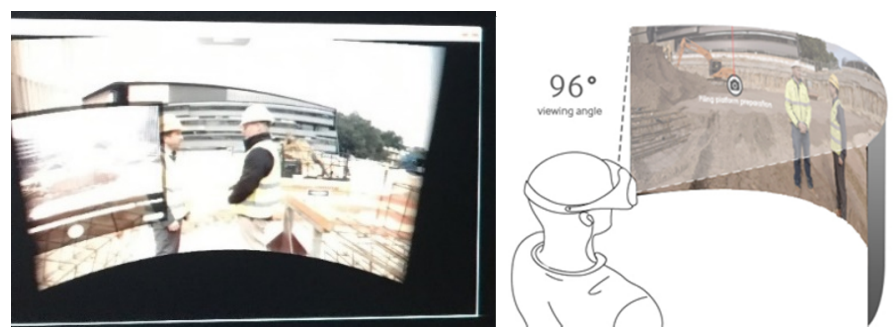

Figure 7. The main computer is running the module in a separate control room.

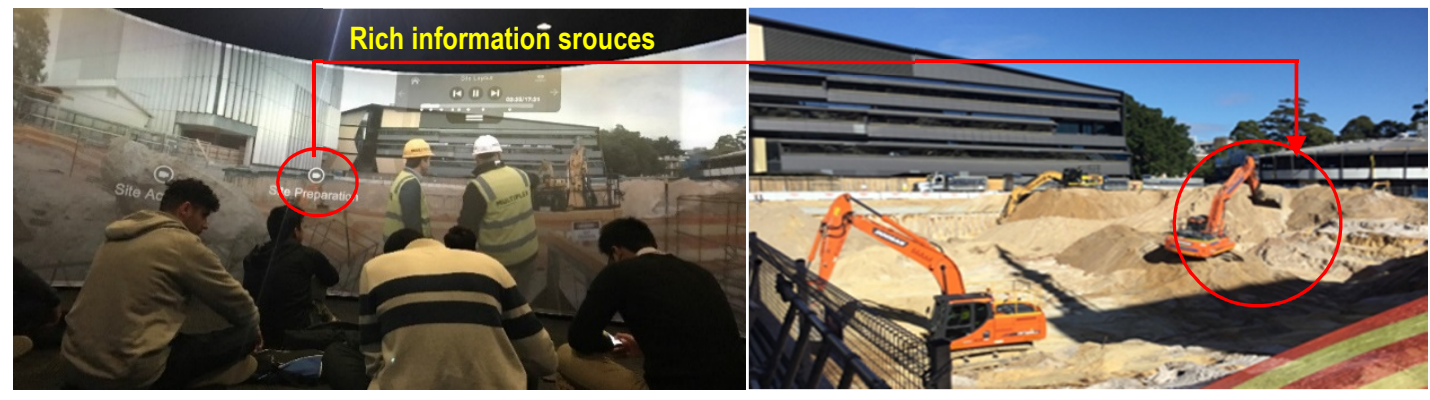

Figure 8. The immersive environment used for the case course at the University of New South Wales (UNSW) (right), A selected Hotspot Site Layout Interview-Bulk excavation (left), the produced module, including the hot spots linked to rich information for each topic.

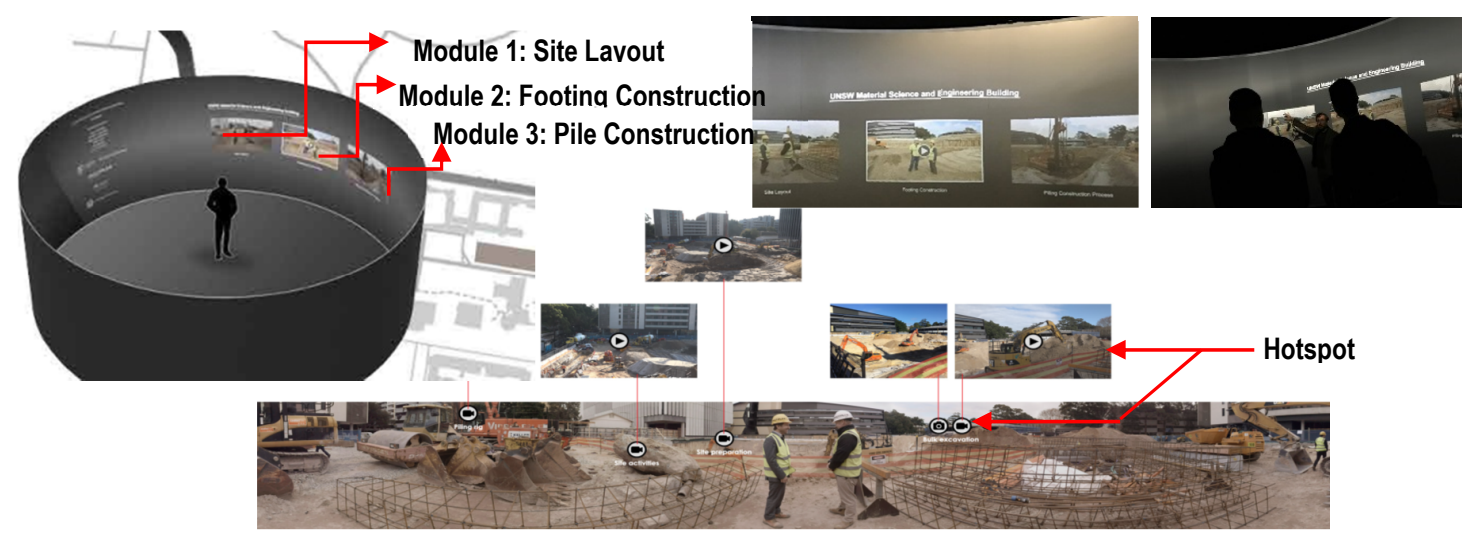

Figure 9. Three modules, including hotspots in the cylindrical theatre (VR Cinema). The construction site, including hotspots linked to 360 videos available to students.

\subsection{Virtual Tunnel Boring Machine}

The third online module (refer to Figure 2) is called VTBM. It is a game-based virtual environment allowing students to explore how a tunnel boring machine is working underground. This module provides a step by step process involving interactive virtual equipment, where students located in different areas inside or outside the university. They can enter virtually into the VTBM together (Figure 10). The number of students or groups of students allowed into the immersive virtual 
environment is not limited. Each tutor or student can invite up to ten students to join simultaneously and participate as group members to explore the immersive virtual environment together. The VTBM enables them to have the same experience with voice communication available and named avatars for all group members who can then see each other in the VTBM space underground. In VTBM, all students can walk individually through the virtual underground environment and explore different areas of the TBM located underground. In the virtual tour underground, they examine components and tasks relevant to TBM operations such as the cutter head, excavation chamber, mixing arm, bulkhead, screw conveyor, erector, tail skin, tunnel lining, hydraulic cylinders, and the backfilling process. The VTBM is based on a general 3DMax model of a tunnel and some images (e.g., 360 and 3D) collected from different activities so students will be able to explore more realistic underground movements and the TBM operation from any angle using a laptop or a HTC Vive headset.
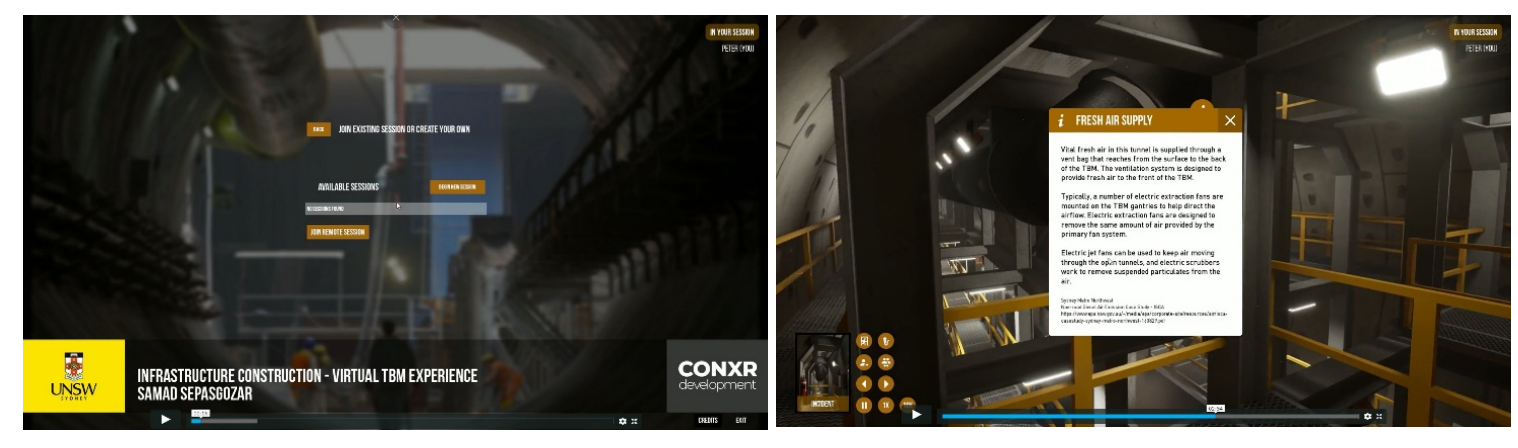

Figure 10. Screenshots from the login page (left), and one of the information hot spots on the VTBM (right). Several hotspots were embedded into the VTBM, referring to some interesting learning points in different parts of the module.

The VTBM is a multiplayer operation system module (See Figure 11), which can be used alongside Discord and Hamachi. Hamachi is required when the tutor allows more than one remote student on a different network outside the university to connect as if they are on the same network. Hamachi is a separate application that creates a type of virtual network over the internet. Students can discuss all components while exploring the TBM by using their device's microphone since there is a voice communication option that allows students to communicate with their teammates using Discord. Discord is an optional tool and should be installed separately. This will enable tutors to invite students into channels (potentially one channel per class) and keep the voice conversation continuous and transparent before and after the networked TBM experience is in action.
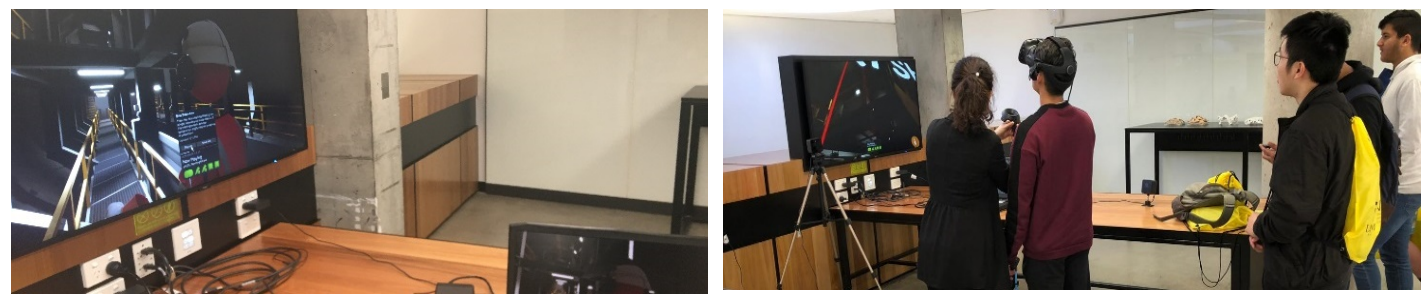

Figure 11. Utilising the VTBM on a large screen in an open studying space at FBE (left) and experiencing the VTBM using both a monitor and an HTC Vive Pro headset with another user logging into the VTBM from a different place in a collaborative multiplayer manner (right).

In a VR environment, there are 10 ordered drop-in locations, including appropriate thumbnail images, which let students experience ten specific identified sites and read the content provided on the hotspots (See the menu in Figures 9 and 12). Among the hotspots, one represents fresh air, and another refers to an air leak incident describing a fault and its consequences. These hotspots can be useful for risk registration and risk analysis. 


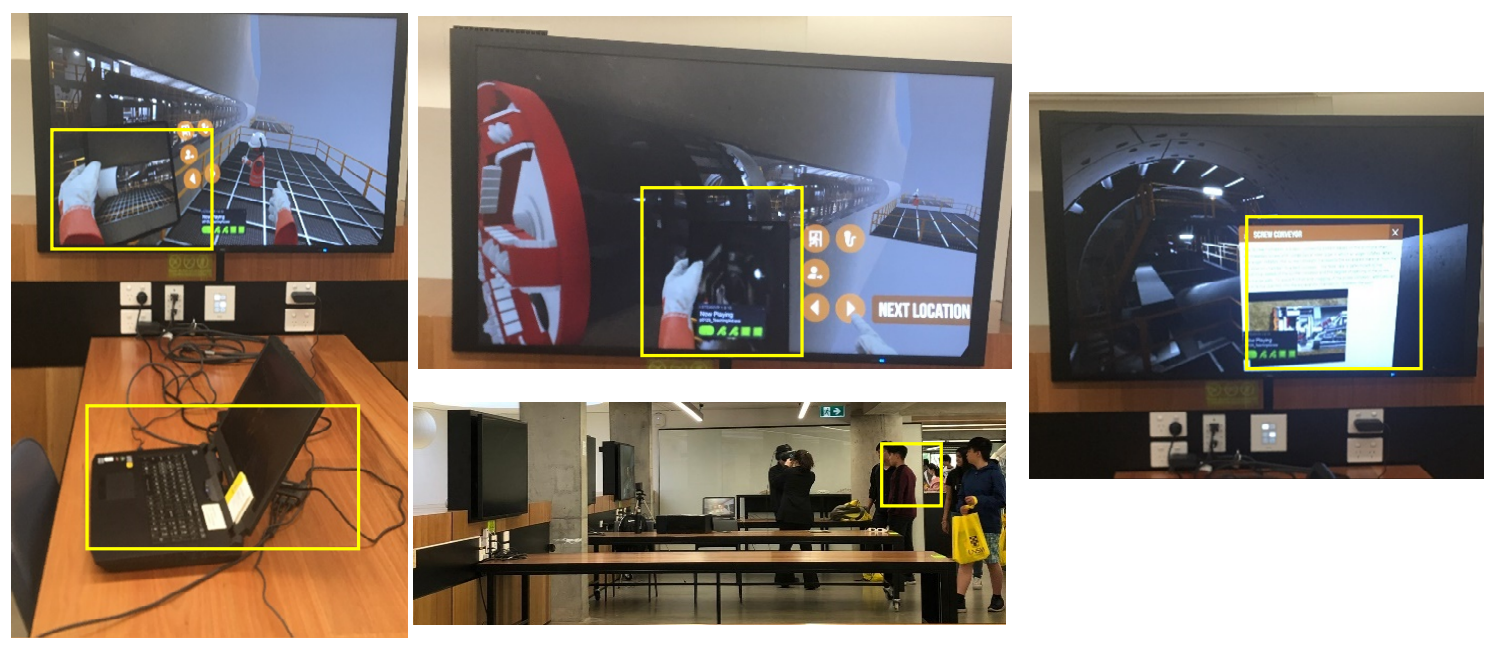

Figure 12. Screenshots from the menu and different sections.

\subsection{PAR}

The fourth online module (refer to Figure 2) is called 'FBE Piling AR' (PAR). FBE refers to the Faculty of Built Environment. The PAR is an interactive virtual environment that goes beyond the traditional pages of a textbook or PowerPoint and enables the foundation construction process to be explained in $4 \mathrm{D}$ (3D spatial models plus time). Students will have the ability to play through the animation of the developed typical example of the construction foundation piling work that supports the building. The PAR is an augmented reality app that is available on AppStore or Google Play to all global users. FBE can students download it, and with additional information provided in the course, they will experience the different processes of building construction, particularly piling methods and various types of piling failures. FBE's students can answer relevant quiz questions available on their course webpage on Moodle.

PAR was developed in two main versions: one version can be downloaded on smart devices (e.g., phones or tablets), and another version is available on Oculus headsets. An unlimited number of students can use PAR. However, if they want to experience the gaming environment as a group, up to ten students can enter into PAR simultaneously. Then they can see avatars in the headset representing their teammates. Avatars can see and ask each other questions when experiencing a different section of the App on the headset version. The avatars' appearance can be edited in Oculus Home, the virtual living room which a student launches into when the student puts on a Rift headset. They can save their experience in the augmented reality environment as a video or image formats, either to use the visual material later or to share/communicate their expertise with others/friends on Facebook.

PAR was designed for collaborative, interactive, and engaging practice and includes eight sections, as shown in Figure 1. It represents the construction process undertaken for a multi-story building and provides insights into structural foundation piles for students. The construction process covers site establishment, piling, and constructing the entire structure. The PAR experience is collaborative, i.e., all users see the same model in their VR headsets, allowing exploration and discussion as a group. The collaboration mechanism was enabled using Oculus Quest headsets (Figure 13) connected via a local Wi-Fi network. PAR offers both a mobile-based AR experience and an Oculus headset experience to learn from a construction case study project. In particular, students can observe different types of failure modes of foundation piles. Students across both platforms can view simplified structures and failure modes of the structural foundation elements (Figure 13).

The experience shows how the structural foundations of the building can fail due to the quality of the piling. The experience includes a foundation pile construction animation showing the entire construction process, including heavy equipment such as a drilling rig and excavator in different sections of the virtual animation. This animation gave the student the ability to explore the model 
section by section, and students were provided with additional information via hotspots around the model. The PAR model is based on 3D models of the Materials Science \& Engineering building and the Kensington campus. The BIM file of that building, campus geographic information system (GIS) data [68] and light detection and ranging (lidar) data providing building height in a 3D context [69,70], were valuable in illustrating the built environment based on a real building. The BIM data available from the case study was used for representing different elements of the building from a pile to a completed building facade. PAR allowed students to look at the structural 'anatomy' of the selected structure (Figure 14) via a mobile device's AR interface or a VR headset (Oculus Quest).
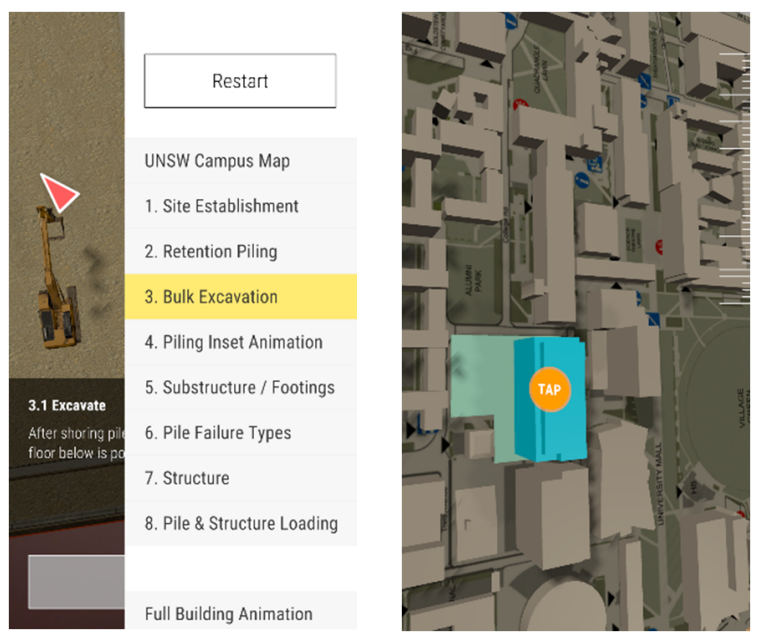

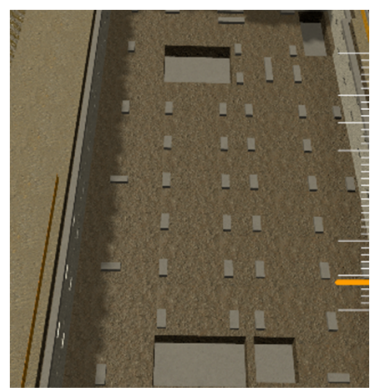

\section{Pile Failure Types}

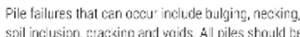
'nomal' anc consisucted wit tout deleces lo the des specifico ions. Once the engineers are teppy with the

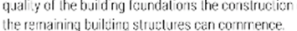

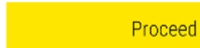

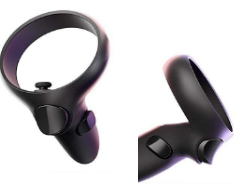

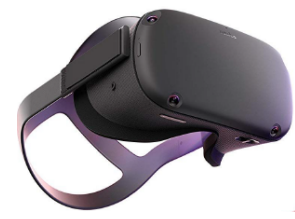

Figure 13. VR hardware for the collaborative model experience- the Oculus Quest.
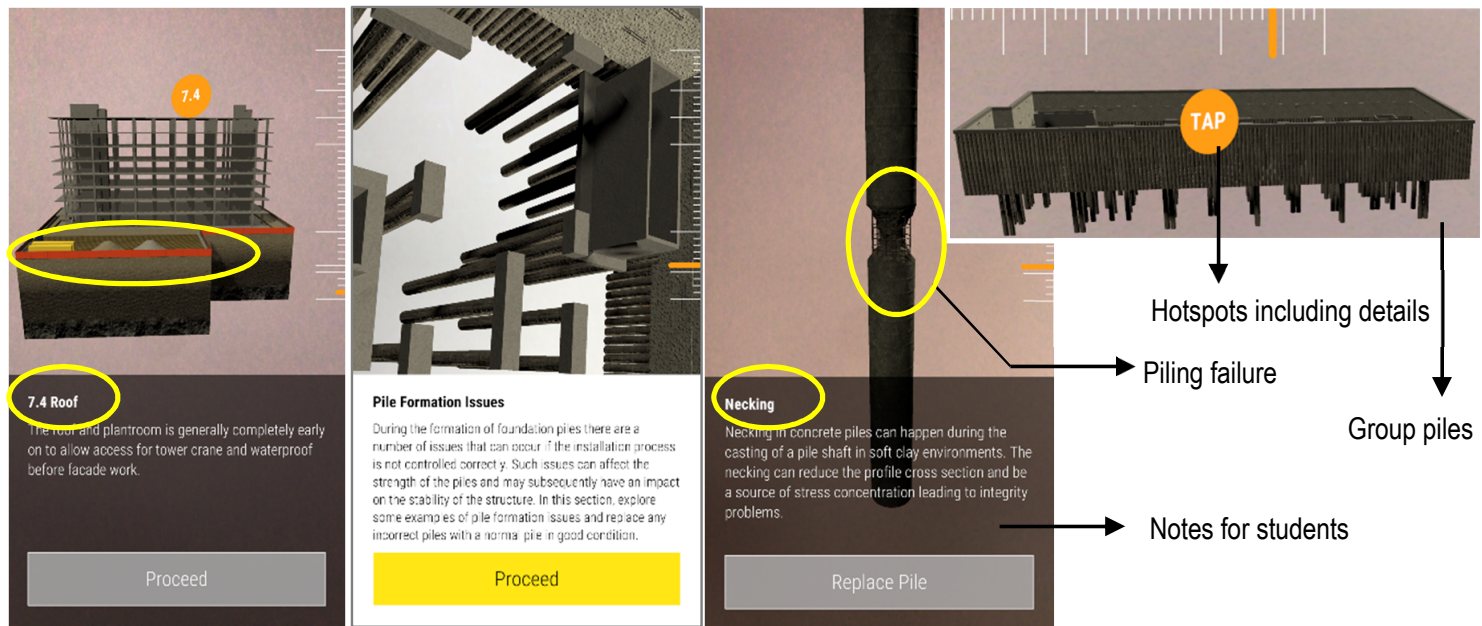

Figure 14. The collaborative model experience is presenting the entire structure and piling systems.

There is an introductory screen in the application to guide the students in how to complete the experience. If there are questions about the visualisation experience, students can ask the instructor or post their queries into a forum created on a learning management system (LMS) such as Moodle. In summary, the PAR offers (Figures 13 and 14):

(i) An ability for students to look at the 'anatomy' of the structural foundations of the selected typical 3D building model;

(ii) Inclusion of a simple foundation construction sequence showing the different phases of a pile formation; 
(iii) The opportunity for students to interact with information hot spots positioned around the model in 3D;

(iv) Views of the structures and typical failure modes of the foundation piles;

(v) AR phone app via the Apple or Android Apps if students use a compatible device (iPhone 6 or newer and AndroidS7 or newer), free to download for everybody;

(vi) Multiplayer VR experience of the 3D building model viewed within Oculus Quest headsets on the same local Wi-Fi network;

(vii) Visualisation and game experience on students' mobile devices (iPhone 6s or newer and Android S7 or newer); and

(viii) Visualisation on Oculus Quest headsets.

\subsection{Digital Twin (DT)}

The fifth online module (refer to Figure 2) is an excavator digital twin that is linked to a physical entity of an excavator. The DT module provides a virtual excavator so students can use it to learn different movements of the excavator. This is a step forward toward using a digital twin for education purposes. The connection between the digital twin and the physical twin required to be on campus, but using the digital version for simulation and students' practice is possible since it was developed for virtual education. This practice may change the educational approach for practice-based courses, as shown in Figure 15.

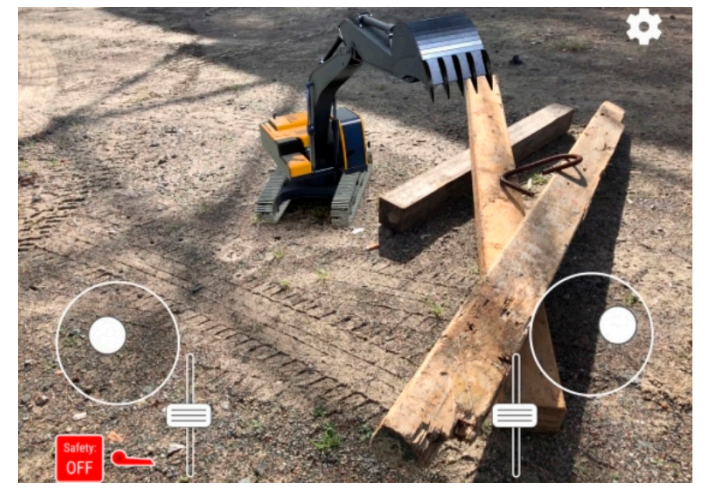

(a)

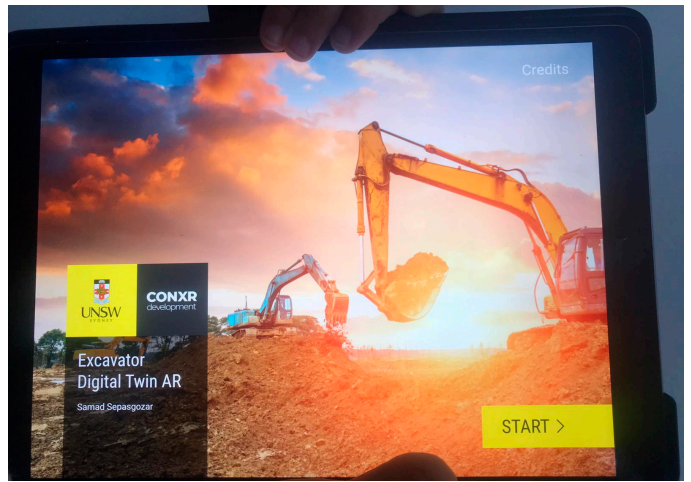

(b)

Figure 15. The digital twin $A R$ of the chosen excavator. (a) the AR excavator running in the field (https://www.globalconstructionreview.com/innovation/australian-academic-develops-digitaltwin-digger/); (b) the digital model on iPad.

\section{Interviews Results and Group WiKi Project Analysis}

In order to address the research questions of what factors may enhance students' engagement and identify the advantages of virtual technologies, a group of students were invited to participate.

The GWiP documents of 204 students were also screened to identify how students played their roles and how they engaged in their projects. A group of ten students participated in the interviews to discuss their experience of using at least one of these technologies. Students were selected from the undergraduate program of construction management. Students were asked to focus on their roles, which have been taken in an infrastructure project and describe the challenges in their projects. Table 5 shows that they adopted their roles and learned about it. For example, one of a student described her role as a project director: "During my role as Project Director for the Sydney Light Rail Project thus far, many various obstacles have arisen. This is largely due to the size of the project and the high stakes the project holds for those involved in its construction and the impact the infrastructure project would have on the people of Sydney". 
The result of the analysis of interviews about learning experience during the module design sessions shows the usefulness of virtual modules as well as limitations, which should be investigated in the future. The value and future research directions are discussed as following. Usefulness is a crucial factor in technology adoption and has been examined in the information systems [71] and construction over the years [64].

The participants support the claim that virtual modules, including the iCRT, provide an innovative immersive environment that brings real construction practices into universities to enable thousands of students from AEC to become familiar with state of the art in a no-risk environment $[72,73]$. Among these modules, the iCRT was recently experienced by over 1000 students. A student says: "It was more in-depth, and with the questions in the interactive exercises, we got to learn much more than just a YouTube video." Another student expressed the feeling that they visited a real construction site and learned from the visit: "I felt I was on an excursion on-site. It gave me knowledge and insight [into] what actually is involved in a construction site". Table 6 represents a summary of the student experience through the modules.

From the students' perspective, by "becoming immersed" in iCRT modules, a greater sense of "motivation and drive to seek further knowledge on key site elements" has been evident. This includes active engagement within quizzes of the quarry module, where trucks were used to underline the importance of Personal Protective Equipment. The modules provided to students have allowed the cohort to excel in "not just university, but also the workplace" by applying key aspects learned through the modules in the field as a student describes. A student expresses:

“When I first stepped on-site, it was a bit daunting. However, I quickly remembered key concepts of the site layout modules I learned in the VR labs and applied my knowledge to assist in site coordination and asserting the traffic management plan."

Several critical benefits have arisen from the application of virtual reality modules. Students can investigate how "productivity measures" are taken place through $360^{\circ}$ cameras. An example of this practice includes the number of cycles an excavator takes to fill a truck from the bulk excavation. And through the alteration of crucial selections, the rate of productivity is evident, highlighting the emphasis of efficiency on site, correlating to both cost and time savings. Students have a real feel of the back of house cost and efficiency management, which can be applied on-site first hand in the field. Another benefit is the visualisation of machinery in practice and how events co-occur, highlighting the "concept of critical paths" as a student describes. "We were learning about Gantt charts and how activities have predecessors, and it was great to see how these activities were linked to successfully deliver a section of activities such as the laying of sheet piles." The concept of "peering beyond the hoardings' highlights the unique experience of VR, producing "a depth of knowledge which cannot be gained unless on-site" one student states. Thus, the module including hotspots with additional and detailed information allowing for greater access to information, which in turn makes students more employable by increasing knowledge and skill base. Table 7 shows the key factors of virtual technologies from students' perspectives. The experience of an immersive environment is hugely enriching compared with just reading a textbook or looking at slides about the construction process.

Table 8 shows that virtual technologies allow for greater insight into construction methodology, expanding exposure to on-site practices. Activities included underground piling, excavating, and mining modules, focusing on the array of different aspects, including operations and risks involved. The virtual technologies directly complemented course content learned in lectures and tutorials where blasting of rock was seen, and shotcrete applied. This provides an insight into construction operations that occur mainly underground and cannot be seen unless on site. The virtual technologies encapsulate students through an innovative medium to transfer vital knowledge about construction, "safety, and scale of operations". This includes "visualising a piling rig's height in comparison to a human on-site with appropriate PPE" as one student describes. "It was great to see the whole operation of the footing system from the piling rigs drilling holes to the reinforcement being in place and finally in situ concrete being poured and capped off to create piles." The depth of knowledge can be seen as students have indicated the positive effect of VR in conveying construction methodologies and procedures. 
Table 5. Summary of results based on the initial assessment and GWiP texts.

\begin{tabular}{|c|c|}
\hline Expected Learning Outcomes & Student Learning \\
\hline Understand scopes, components, and characteristics of national and international IIC projects & $\begin{array}{l}\text { All groups selected one related project and described the characteristics of the project. } \\
\text { For example: "The main goal is to renew the CBD's urban landscape and mitigate } \\
\text { congestion" } 8998 \text { Group C, and "This report provides an analysis of construction processes ... through } \\
\text { investigating the cross-London railway, Cross-rail ... composing of } 42 \mathrm{~km} \text { worth of tunnels ..." } \\
\text { Group 10395-North Connex }\end{array}$ \\
\hline $\begin{array}{l}\text { Understand the mechanisms, operation systems, performance and components of a variety } \\
\text { of contemporary national and international IIC projects }\end{array}$ & $\begin{array}{l}\text { The groups demonstrated that they understand the construction operation systems in their } \\
\text { construction projects. For example, one of the groups (10029-Flying High Airport) discusses how } \\
\text { the location of their tower crane should be determined. For example, "The level by level approach } \\
\text { requires } 3 \text { 20t excavators to be lifted up to the top level with hammer attachments to demolish walls and } \\
\text { slabs which would create a larger dust and vibration disturbance to the community." } 8998 \text { Group C }\end{array}$ \\
\hline $\begin{array}{c}\text { Increase your ability to critically analyse IIC projects to explore strategic, tactical and } \\
\text { operational challenges and suggest improvement scenarios }\end{array}$ & $\begin{array}{c}\text { All groups tried to demonstrate their ability to analyse their project. For example, a group } \\
\text { member explains: "... The successful management of Cross-rail is only made possible by various layers } \\
\text { of project organisation focusing on their prescribed roles, with [a] key focus on deep construction } \\
\text { understanding. This report finds that understanding construction processes will lead to beneficial } \\
\text { outcomes, but obstacles that halt construction progress require active monitoring and key actions by } \\
\text { management." Group 10395-North Connex }\end{array}$ \\
\hline $\begin{array}{c}\text { Enhance communication skills (i.e., professional writing and acting) and demonstrate how to } \\
\text { work effectively in teams }\end{array}$ & $\begin{array}{l}\text { The project is role-play based, and all of [the] students create videos and write on their Wiki } \\
\text { pages, so they demonstrate their verbal and written communication skills. }\end{array}$ \\
\hline
\end{tabular}


Table 6. Features identified from the analysis of student experience from selected modules.

\begin{tabular}{|c|c|c|}
\hline Key Factors and iCRT Features & Benefit & Students Experience and Feedback (Quotes) \\
\hline Usefulness: Scanning the entire site & $\begin{array}{l}\text { Clarity within the lessons regarding construction } \\
\text { excavation processes }\end{array}$ & Step by step modules, on-site layout and footing construction assisted greatly. \\
\hline Usefulness: Activity Analysis & $\begin{array}{l}\text { Recognising the scale, size, and type of drilling and } \\
\text { excavating equipment }\end{array}$ & $\begin{array}{c}\text { "As I had no on-site experience, it was extremely interesting to see the scale, size, } \\
\text { and type of drilling and excavating equipment used on site. This included a man } \\
\text { standing next to an immense piling rig, ultimately showcasing the mammoth operations } \\
\text { undertaken on site." }\end{array}$ \\
\hline Rich sources of information: Hotspots (See Figures 8 and 10) & $\begin{array}{l}\text { Hotspots provide me with rich content emphasising the } \\
\text { significance of specific objects on site }\end{array}$ & $\begin{array}{l}\text { Vividly indicates images of a piling rig, before, during and after shots to } \\
\text { underline the concept of the activity to clarify construction techniques }\end{array}$ \\
\hline Immersion: VR Cinema room/Innovation & $\begin{array}{l}\text { An authentic learning environment that immerses me into } \\
\text { the excavation and piling process despite being physically } \\
\text { inside a classroom }\end{array}$ & $\begin{array}{l}\text { "The VR and } 360 \text { videos were unlike any tutorial or learning experience I had seen. } \\
\text { It engaged me in an interesting medium, and I felt like I learned a lot more than regular } \\
\text { tutorials and lectures from other subjects within the Construction Management degree." }\end{array}$ \\
\hline Enjoyment: Use of 3D Glasses and screens & Increases my interest in learning the subject & $\begin{array}{l}\text { Innovation in technology has allowed for 3D glasses to be used within VR labs, } \\
\text { creating a degree of realism. Through these innovative methods of teaching, } \\
\text { we have students who have had an increase in interest in learning the subject. }\end{array}$ \\
\hline Situated learning and Interrelated Concepts & $\begin{array}{l}\text { Helps to relate previous knowledge to new information } \\
\text { about excavation processes }\end{array}$ & $\begin{array}{l}\text { Knowledge gained through other subjects in university complemented further } \\
\text { information learned through the VR Cinema. In combining both, I was able to } \\
\text { display my skills both at university and on-site effectively. }\end{array}$ \\
\hline
\end{tabular}


Table 7. Students' reflection and critical factors of the VR application based on semi-structured interviews.

\begin{tabular}{|c|c|c|}
\hline Learning Outcome/Useful Features of the Module & Key Factor & Selected Quote \\
\hline \multirow[t]{2}{*}{ Required equipment for each construction task } & Situated learning: types of machinery & $\begin{array}{l}\text { "... construction machinery is explicit [clear to us], but the use of it } \\
\text { [applications] is difficult to know about it and understand .. how the machine } \\
\text { works and the types of machinery..." } 8.08 \text { HUST01 }\end{array}$ \\
\hline & How machinery work & $\begin{array}{c}\text { "Different [types of] machinery and the processes and .. how the machinery moves } \\
\text { the dirt stuff..." }\end{array}$ \\
\hline Human resources and management & How to allocate people and machinery to a specific task & $\begin{array}{c}\text { "Consolidated my knowledge about how different machinery and different people } \\
\text { that worked on site ..." } 03.02\end{array}$ \\
\hline Deep understanding of processes and tasks & Detailed information for each component or task & $\begin{array}{c}\text { "The hot points ... you can click on it, and you get more information and how } \\
\text { interviewing people that work on the site ..." } 01.51\end{array}$ \\
\hline Engaging students & Online feedback & $\begin{array}{l}\text { "Quizzes at the end of the video were interesting .. we could reflect on that some } \\
\text { main points" } 01.38\end{array}$ \\
\hline Overview of the magnitude of operations & The scale of the construction site & $\begin{array}{l}\text { "It was great to see just how many vehicles and machinery are involved in bulk } \\
\text { excavation and how many machines are operating around the site." }\end{array}$ \\
\hline Deep understanding of construction operations & $\begin{array}{l}\text { Rich sources of information: } \\
\text { Predecessors of construction processes }\end{array}$ & $\begin{array}{l}\text { "The twenty-minute modules allowed us to see the whole process of a piling rig } \\
\text { from digging the hole to inserting the cage, in-situ concrete, and capping off; we } \\
\text { were able to see the predecessors of the method." }\end{array}$ \\
\hline The conceptualisation of essential on-site practices & Labour and trades on-site & $\begin{array}{l}\text { "Being in the first year, we don't get to visit the construction site and have no } \\
\text { construction experience under our belt, so being able to visualise how } \\
\text { construction personnel works efficiently together was interesting." }\end{array}$ \\
\hline Operational safety awareness & Personal Protective Equipment & $\begin{array}{c}\text { "After seeing the scale of operations and sitting through a few modules, I was able } \\
\text { to see what the potential impact of a downfall could look like after identifying a } \\
\text { variety of risks on the construction site." }\end{array}$ \\
\hline Balanced practical and theory learning & $\begin{array}{l}\text { Lectures covering theoretical concepts and VR tutorials } \\
\text { allowing for hands-on experience }\end{array}$ & "The VR and 360 videos complemented the theory we learned in the lectures..." \\
\hline Practical knowledge & Enjoyment & "... as it was interesting to gain some practical experience." \\
\hline Workplace integration & Incorporating relevant principles & $\begin{array}{l}\text { "After looking back seven months, and working within the construction industry } \\
\text { on-site, the information I had learned in the modules became relevant and useful." }\end{array}$ \\
\hline
\end{tabular}


Table 8. Summary of functionalities and benefits of online teaching tools based on the instructor observation and the literature.

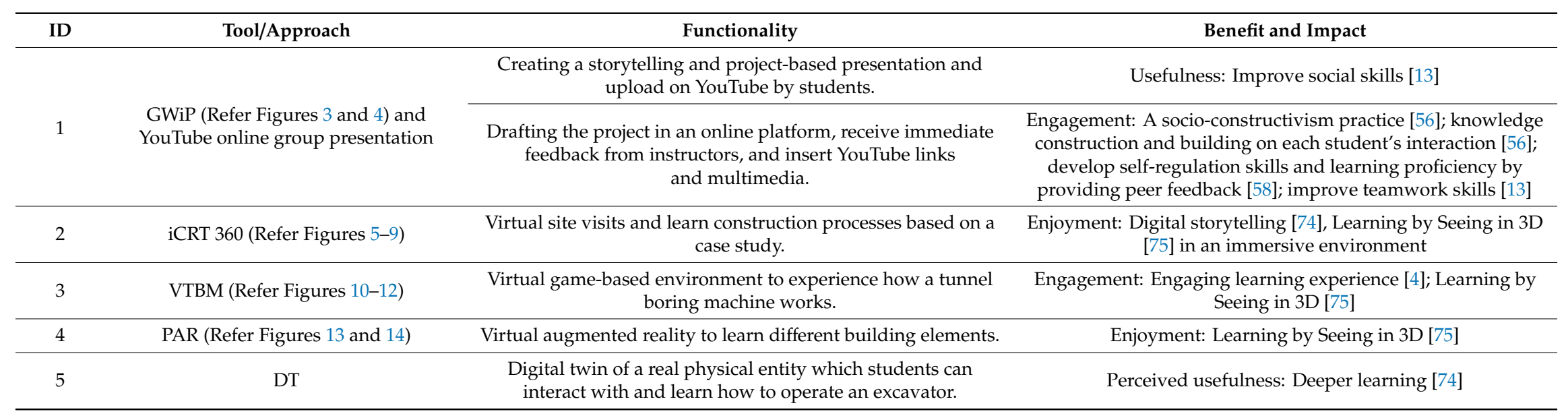




\section{Discussion}

This paper presents six innovative tools, including novel virtual digital applications, which specially developed for virtual teaching. The unique virtual technology implementation and students' feedback show that the use of online virtual tools for learning practical construction courses is feasible and useful. This paper describes how selected course content was designed and improved by utilising different virtual technologies over five years from the time the course was created in 2016. Students' satisfactions gradually have been increased, and the course was received firm quotations recently from students saying that they enjoyed and deeply learned the concepts which were not possible to learn from other resources. The use of virtual online technologies potentially enhances students' experience and engagement in practical construction courses. The immersive education modules have promising benefits to students, who are digital natives and known as tech-savvy [76]. These students have an inherent understanding of new online tools, smartphones, and digital devices. The concept of providing an authentic education space with interactive and engaging modules has seen an increase in the depth of knowledge and alignment with course content. Selected benefits were identified as the successful integration of theoretical concepts into practical experience in an authentic learning environment.

This investigation and modules created on virtual education consider the relevance of the online teaching approaches to allied academic disciplines, such as AEC as well as industry-led employee training. It thus speculates as to the online virtual advantages extending from education to economic deficiency and productivity. Visitors from other disciplines were inspired by the modules presented in this paper, including iCRT, and several leading global contractors and educators appealed to them from different universities.

The online versions of PAR and VTBM are significant educational solutions since they help students to obtain knowledge more rapidly and efficiently. The instructor can now spend more time in the online classroom, explaining other relevant concepts related to the visualised components in $3 \mathrm{D}$ and thus generate a more practical and complete lesson. This particular example of online practice also creates long-lasting knowledge because students are highly engaged in the space with the components of the building or the tunnelling machinery. Compared with a textbook or a lecture, students understand the practicalities and concepts more rapidly and with greater clarity. The produced modules provide an immersive sense of place when walking through a TBM or a building.

The main benefits of these modules are to improve the learning experience by taking students on a field trip in an immersive environment. In the virtual tour, students will experience a virtual representation of a real project and a simulation of a tunnel boring machine. This exposes students to a practical experience which helps them to understand how a tunnel boring machine works, and to learn the different structural elements of a sample building constructed by a leading construction contractor.

The results show that the online virtual tools are valuable and useful to instructors in construction to enhance students learning and assist them to retrieve their gained knowledge in the lecture in the real context. Future research is required to evaluate students' and tutors' perceptions of the model, using post-implementation qualitative data.

The value of this study is significantly high to AEC educators and scholars in this field who are from older generations teaching digital natives. This paper introduces digital practices to these educators who are accustomed to plan, work, and interact with others in a physical world rather than a virtual environment. The technologies presented in this paper can be considered as a subjective norm for or expectations of the digital natives. They have been using online apps and virtual game-based environments from their early years.

Restrictions on face-to-face teaching and learning due to the COVID-19 pandemic created more demand to use these types of advanced online multiplayer tools to replace construction site visits or laboratory experiences. These modules are designed to be useful for both individual learning and group interactions. They are much more comfortable for individuals to comprehend complex topics compared to textbook reading materials about construction processes. For example, students in a group of up to 10 people could see each other as avatars in a gaming environment and could explore different 
areas of the machine, talk about components, and interact with the gaming model. The students experienced the complex components or mechanisms of a machine in VTBM or elements of a building in PAR. The main practical implications of this study are listed as follows: This paper clarified the need and value for designing new online interactive tools for building construction; the practice of effective use of online tools in everyday teaching and learning was discussed; a greater awareness of online interactive tools was made, and relevant design and implementation issues were discussed, and finally a theoretical model was suggested to be examined as future investigation.

Several studies about the mixed reality show significant benefits for students, including improved learning effectiveness ( $76 \%$ more than traditional teaching), engagement, and motivation [77]. By giving students a self-paced interactive virtual learning simulation, students can repeat using the learning materials and experiments without additional costs. The online virtual modules have been designed based on the literature recommendation to include interactive resources such as embedded photos and videos and links to multiple-choice questions. The interactive elements provide different learning scenarios to allow construction students to practice safely and to transfer their knowledge to practice. Where some current commercialised modules simply use expensive digital technologies (e.g., oculus gears and goggles) applicable to small classes, the presented innovative resources were used for massive classes of students. It was not possible to provide oculus gears and goggles to 300 students, and also, it was not possible to take all of them into a construction site. The experimentation showed that the virtual and augmented reality modules gave students a chance to explore building construction processes. They could also experience a tunnel boring machine in operation, identify potential operational risks and hazards (e.g., foundations cracking or leaking issues), and discuss issues while experiencing the immersive environment.

As another example, GWiP is a novel real-time group project model. This model makes the main contributions to the field. First, the GWiP model encouraged students to discuss with piers as each of them takes a role similar to the real projects, and they gave them immediate feedback. Also, tutors could monitor their work in real-time and were able to provide them with feedback when they have any questions. This is in line with the previous recommendation in the literature. For example, Gómez-Pablos et al. [13] discussed that students need help and support for doing their tasks because sometimes they do not know how to work effectively with their group mates or peers. They suggested that their social skills need to be reinforced and improved while doing different tasks at the university [13]. The GWiP helped students to know each other, trusted to peers, and supported each other for constructively accomplishing their assigned works. The role of GWiP model was to allow the opportunity to improve students' interpersonal skills, thereby providing a digital collaboration platform for practising the required skills. The GWiP has also encouraged students to start working on their homework in the workshop under tutors' supervision and continued doing the project outside of class using an online platform under the instructors' supervisor. The GWiP model enabled instructors to examine student's contributions to the group project report in real-time during the semester. However, previous approaches rely on students' judgments that use a different scale of measure.

Based on the interviews, module development experimentation, and the literature, this paper suggests three main factors, including 'perceived usefulness', enjoyment, and engagement as three primary constructs of satisfaction. All these factors can contribute to modelling and predicting virtual technology acceptance. This model is suggested as a conceptual framework that can be examined in different contexts and can be considered as research hypothesis in future studies:

Research question 1: Technology acceptance modelling has a lengthy theoretical background and applied in a different context, but this paper contributes by presenting an extended model applicable to virtual education tools $[64,71,78-80]$. The article shows some factors that can be considered as measures of "usefulness", which is one of the critical constructs of the technology acceptance model $[78,81]$. This paper also suggests that 'usefulness' of the virtual technology refers to students' experience of social presence, the possibility of using a rich source of information, and situated learning, which all help students to comprehend detailed practical information of operation process as shown in Figure 16. 
This is useful since otherwise, it is not possible to obtain the information without involving in a project as a cadet or intern. Figure 16 shows a list of factors identified in interviews and the literature that can be used for modelling and predicting virtual technology acceptance by participants. The proposed model can be examined for different technologies such as DT, VR or web-based virtual technology. The technology can be used for different subjects covering construction operation, risk analysis, safety, and construction informatics.

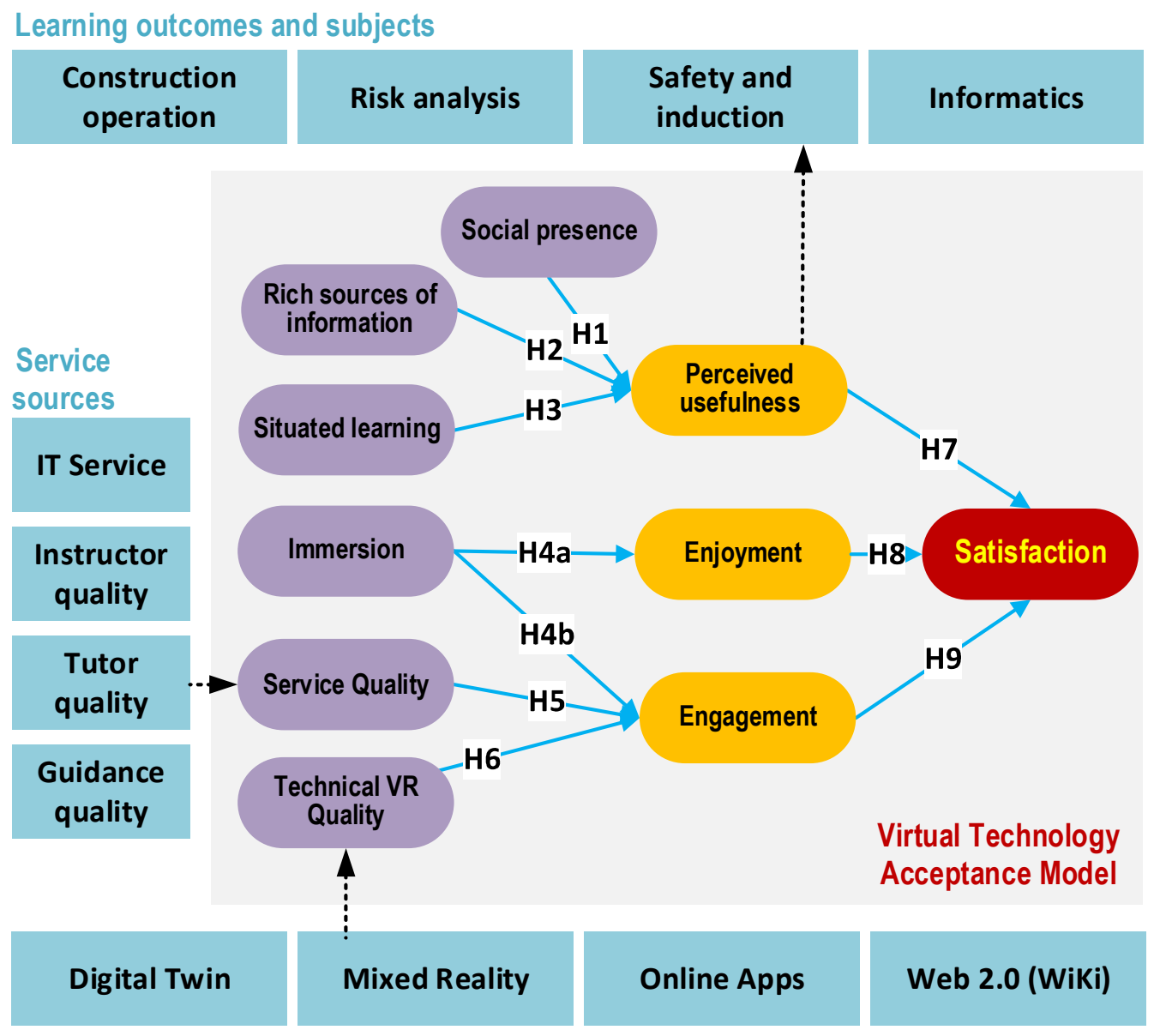

\section{Learning technology types}

Figure 16. A proposed theoretical virtual technology acceptance model developed based on interviews, for measuring VR acceptance by participants.

Research question 2: The proposed theoretical model also can be modified for 360-degree video applications. For example, the following variables can be examined in modelling:

- Explore and comprehend construction site layout planning [76]

- Experience the site layout from a site manager perspective [76]

- Enhance the emotions felt by students

- Present a detailed scenario that can be consulted by students repeatedly if necessary [76]

- Identify risks and hazards related to different activities such as drilling rig. A survey can be conducted based on 'active processing assumption' that suggest meaningful learning may occur if students learners can organise the learning material into a coherent structure, and allow them to integrate it with their prior knowledge about the event $[76,82]$. The survey based on Slater-Usoh-Steed (SUS) [83,84] can be adopted for assessing the level of presence experience. At the same time, students use 360 videos and can rate their experience in terms of their feeling of "being there, realism, involvement" [85]. Another recommended model is Witmer and 
Singer presence (WS) measuring student involvement, sensory fidelity, adaptation or immersion, and interface quality [86]. The post media questionnaire (PMQ) is also useful to design a question for assessing the emotions caused by 360 video exposure in terms of "anxiety, disgust, anger, fury, surprise, relax, happiness, and sadness" [85].

Research question 3: How technology-enhanced education and pedagogical design to increase students learning in practical courses, software teaching, and skilled-based subjects in construction. How different elements of virtual online learning will contribute to collaborative thinking and will enhance students' engagement in software teaching and skilled-based subjects. There is a wide range of new technologies such as light detection and ranging (Lidar) tools [69,81,87-90], data mining [91], deep/machine learning [92,93], geographic information systems (GIS) [70,94], different types of laser scanners [88,95-97], virtual reality, three-dimensional printing [98], building information modeling (BIM) [99-102] and digital twin [68,103] that should be practised and learned by students and new employees. The challenging questions concern 'how technology can be used to teach technology'. These tools are often required for employment. Recent education studies recommended that education mode and assessments should be reframed for enhancing students' skills for employability [104]. The questions raise how digital twin and new teaching tools can help educators to 'implement the constructive alignment model' in different subjects [105]. Some relevant research includes the work of Boje et al. [103] and da Motta Gaspar et al. [106] who intended to address this type of question. Still, both education technology and construction digital technologies are advancing, and thus training approaches are required to be modified based on empirical investigations over time.

Research question 4: Some studies tried to use virtual or tangible replicas as a part of digital twin in archaeology using manipulation interfaces (e.g., SketchFab) in archaeology [107]. However, there was no usage of the digital twin in ACE education. Future studies can continue the use of the digital twin in a different context, transferring different concepts to students how the digital twin and a virtual replica can contribute to education transformation and enhance the immersive environment and students' engagements. How can the learning management system (LMS), including Moodle or collaborative Blackboard, as well as communication tools such as Zoom or Microsoft Teams, support these digital simulations. Constructive alignment is challenging when using a digital device. Most of the technologies offer exciting features, but the question is if they will help the instructor to align further the course learning outcome, activities, and assessments. In fact, the question that should be addressed concerns on how virtual technology is useful in implementing the constructive alignment model in teaching.

\section{Conclusions}

This project was aimed to present a set of novel technologies and practices, which was used for developing a digital pedagogy. They introduced technologies that enable instructors to monitor students' performance and give them immediate feedback in large classes, where the instructor cannot trace students using traditional approaches. The outcomes and delivered materials discussed in this paper covered different topics such as the 'introduction to a construction project' (e.g., UNSW campus and the selected building) as the first section of the PAR, 'sequences of foundation construction' as the second part of the PAR, and 'design construction processes for tunnelling as a specific activity' covered by VTBM. One of the primary purposes of these online mixed reality modules is to improve the learning experience by allowing students to understand how a tunnel boring machine works, and to become familiar with the different structural elements of a building based on practical experience in a virtual environment. The technologies introduced in this paper offer an opportunity to engage students in acquiring and retaining their knowledge, learn practical knowledge of running an excavator or planning for the excavation process in a construction site as well as improving their teamwork and social skills.

The six primary online education tools were developed and presented in this paper by examining many scenario developments, group discussions, evaluations of initial versions, implementation, 
and revisions. There was considerable feedback from students to assess each module before the last updated version was finalised. The development team included experts with different backgrounds, lecturers, students, educational development specialists, industry practitioners, and technology experts. Lecturers, students, and educational development experts were involved in designing the modules to underline its usefulness to instructors and learners. Industry practitioners brought first-hand knowledge and case study information into the modules rather than the theoretical information available in textbooks. Details of each education module were discussed in the paper.

This paper is a step forward towards the implementation of a fully online immersive teaching experience in construction, while there are limited practices of the digital twin in the construction education context. The paper presents the potential of online mixed reality in construction education while it has not been thoroughly investigated in line with the advances made in technology development. The recent growth in virtual reality hardware and devices has increased the applicability of mixed reality practices and their ease of use.

The paper also presented the role-play group project model, including individuals and group activities and tasks. The model is implemented on an online platform. The application is beyond 'sharing information in $\mathrm{WiKi}^{\prime}$ ', and it helps the student to assist each other, give immediate feedback, and correct each other on the report. The implementation of the model has many advantages comparing the current methods discussed, such as:

(1) The instructor can monitor groups or individuals whether they are continually making progress, and which group is waiting for the last week of the semester to do the job

(2) Students can get immediate feedback from their team members and the instructor (lecturer and tutors)

(3) The instructor can see the history of all changes, edits, and corrections have done by students.

The contributions of this paper are to extend the body of knowledge in building construction by presenting novel technological applications of digital twin and mixed reality in the construction context. The forms and design development process also present theoretical factors influencing the learning construction process, which increases the learner competency.

The implications of this paper are to present a novel technological approach for building and tunnelling construction education and professional training. Construction project managers can use this approach for two purposes: project induction and training construction operation to novice practitioners. This paper also clarifies the value for designing new online interactive tools for building construction, discusses the effectiveness of online tools in everyday teaching and learning, and raises awareness of online interactive applications in construction education and businesses. This paper presents the outcome of expensive experimentation, which is extremely valuable to construction educators who are from older generations to digital natives. This paper introduces practices to these educators who are accustomed to plan, work, and interact with others in a physical world rather than a virtual environment. However, the technologies presented in this paper can be counted as a subjective norm or expectations of the digital natives. They have been using online apps and virtual game-based environments from their early years. This paper also suggests a plan for future studies, including valuable research issues discussed in the discussion section. The article was limited to presenting potential solutions to the need for virtual reality modules, and the qualitative study limited to examine three modules. Thus, more empirical investigations are required, including surveys, to evaluate each module using a larger group of participants familiar with the virtual apps and tools presented in this paper.

Funding: This research received no external funding.

Acknowledgments: The practice supported by the Scientia Education Investment Fund (SEIF 2018-2019) and Research Infrastructure Scheme (RIS) at the University of New South Wales, Sydney. With thanks to the participation of instructors, students, technical practitioners, and industry partners and the Construction Mixed Reality Development (CONXR UNSW) stakeholders.

Conflicts of Interest: The authors declare no conflict of interest. 


\section{References}

1. Sepasgozar, S.M.E.; Bliemel, M.J.; Wang, C. A Flipped classroom model to teach skill-based contents for a large construction technology course. In Proceedings of the 40th AUBEA 2016, Radical Innovation in the Built Environment, Cairns, Australia, 6-8 July 2016.

2. Liu, J.; Wang, Q.; Liang, S.; Zhang, Z. Design of virtual reality combined with blended experimental teaching mode. In Proceedings of the 2019 International Conference on Advanced Education Research and Modern Teaching (AERMT 2019), Jinan, China, 28-29 September 2019.

3. Lee, V.W.; Hodgson, P.; Chan, C.-S.; Fong, A.; Cheung, S.W. Optimising the learning process with immersive virtual reality and non-immersive virtual reality in an educational environment. Int. J. Mob. Learn. Organ. 2020, 14, 21-35. [CrossRef]

4. Lee, A.L.; DeBest, M.; Koeniger-Donohue, R.; Strowman, S.R.; Mitchell, S.E. The feasibility and acceptability of using virtual world technology for interprofessional education in palliative care: A mixed methods study. J. Interprof. Care 2019, 1-11. [CrossRef] [PubMed]

5. Bashabsheh, A.K.; Alzoubi, H.H.; Ali, M.Z. The application of virtual reality technology in architectural pedagogy for building constructions. Alex. Eng. J. 2019, 58, 713-723. [CrossRef]

6. Wang, R.; Lowe, R.; Newton, S.; Kocaturk, T. Task complexity and learning styles in situated virtual learning environments for construction higher education. Autom. Constr. 2020, 113, 103148. [CrossRef]

7. Eiris Pereira, R.; Gheisari, M. Site visit application in construction education: A descriptive study of faculty members. Int. J. Constr. Educ. Res. 2019, 15, 83-99. [CrossRef]

8. Gao, Y.; Gonzalez, V.A.; Yiu, T.W. The effectiveness of traditional tools and computer-aided technologies for health and safety training in the construction sector: A systematic review. Comput. Educ. 2019, 138, 101-115. [CrossRef]

9. Jensen, L.; Konradsen, F. A review of the use of virtual reality head-mounted displays in education and training. Educ. Inf. Technol. 2018, 23, 1515-1529. [CrossRef]

10. Feng, Z.; González, V.A.; Amor, R.; Lovreglio, R.; Cabrera-Guerrero, G. Immersive virtual reality serious games for evacuation training and research: A systematic literature review. Comput. Educ. 2018, 127, 252-266. [CrossRef]

11. Checa, D.; Bustillo, A. Advantages and limits of virtual reality in learning processes: Briviesca in the fifteenth century. Virtual Real. 2020, 24, 151-161. [CrossRef]

12. Han, S.; Capraro, R.; Capraro, M.M. How science, technology, engineering, and mathematics (STEM) project-based learning (PBL) affects high, middle, and low achievers differently: The impact of student factors on achievement. Int. J. Sci. Math. Educ. 2015, 13, 1089-1113. [CrossRef]

13. Basilotta Gómez-Pablos, V.; Martín del Pozo, M.; García-Valcárcel Muñoz-Repiso, A. Project-based learning (PBL) through the incorporation of digital technologies: An evaluation based on the experience of serving teachers. Comput. Hum. Behav. 2017, 68, 501-512. [CrossRef]

14. Johnson, D.W.; Johnson, R.T. An educational psychology success story: Social interdependence theory and cooperative learning. Educ. Res. 2009, 38, 365-379. [CrossRef]

15. James, K.; Humphrey, G.; Vilis, T.; Corrie, B.; Baddour, R.; Goodale, M. "Active" and "passive" learning of three-dimensional object structure within an immersive virtual reality environment. Behav. Res. Methods Instrum. Comput. 2002, 34, 383-390. [CrossRef] [PubMed]

16. Horne, M.; Thompson, E.M. The role of virtual reality in built environment education. J. Educ. Built Environ. 2008, 3, 5-24. [CrossRef]

17. Wang, P.; Wu, P.; Wang, J.; Chi, H.-L.; Wang, X. A critical review of the use of virtual reality in construction engineering education and training. Int. J. Environ. Res. Public Health 2018, 15, 1204. [CrossRef]

18. Klotz, L.; Grant, D. A balanced view of sustainability in civil engineering and construction. In Proceedings of the Construction Research Congress, Seattle, WA, USA, 5-7 April 2009; pp. 1338-1347.

19. Lin, C.-C.; Tsai, C.-C. The relationships between students' conceptions of learning engineering and their preferences for classroom and laboratory learning environments. J. Eng. Educ. 2009, 98, 193. [CrossRef]

20. Yeary, M.; Yu, T.-Y.; Palmer, R.; Biggerstaff, M.; Fink, L.; Ahern, C.; Tarp, K. A hands-on, interdisciplinary laboratory program and educational model to strengthen a radar curriculum for broad distribution. J. Adv. Eng. Educ 2007, 1, 1-23. 
21. Leicht, R.M.; Lewis, A.; Riley, D.R.; Messner, J.I.; Darnell, B. Assessing traits for success in individual and team performance in an engineering course. In Proceedings of the ASCE Construction Research Congress, Seattle, WA, USA, 5-7 April 2009; pp. 5-7.

22. Toto, R.; Nguyen, H. Flipping the work design in an industrial engineering course. In Proceedings of the Frontiers in Education Conference, FIE'09. 39th IEEE, San Antonio, TX, USA, 18-21 October 2009; pp. 1-4.

23. Monson, M.C.; Homayouni, H.; Dossick, C.; Anderson, A. Improving the understanding of BIM concepts through a flipped learning lab environment: A work in progress. In Proceedings of the ASEE 122nd Annual Conference \& Exposition, Seattle, WA, USA, 14-17 June; pp. 14-17.

24. Wang, S.; Cheah, C.Y.; Chew, D.A. Dynamics of strategic management in the Chinese construction industry. Manag. Decis. 2005. [CrossRef]

25. McWhirter, N.; Shealy, T. Case-based flipped classroom approach to teach sustainable infrastructure and decision-making. Int. J. Constr. Educ. Res. 2020, 16, 3-23. [CrossRef]

26. Lee, S.J.; Ngampornchai, A.; Trail-Constant, T.; Abril, A.; Srinivasan, S. Does a case-based online group project increase students' satisfaction with interaction in online courses? Act. Learn. High. Educ. 2016, 17, 249-260. [CrossRef]

27. Finlay, S.-J.; Faulkner, G. Tête à tête Reading groups and peer learning. Act. Learn. High. Educ. 2005, 6, 32-45. [CrossRef]

28. Bahar-Özvaris, S.e.; Çetin, F.Ç.; Turan, S.; Peters, A.S. Cooperative learning: A new application of problem-based learning in mental health training. Med Teach. 2006, 28, 553-557. [CrossRef] [PubMed]

29. Herrmann, K.J. The impact of cooperative learning on student engagement: Results from an intervention. Act. Learn. High. Educ. 2013, 14, 175-187. [CrossRef]

30. Hall, D.; Buzwell, S. The problem of free-riding in group projects: Looking beyond social loafing as reason for non-contribution. Act. Learn. High. Educ. 2012, 14, 37-49. [CrossRef]

31. Hassanien, A. A qualitative student evaluation of group learning in higher education. High. Educ. Eur. 2007, 32, 135-150. [CrossRef]

32. Radianti, J.; Majchrzak, T.A.; Fromm, J.; Wohlgenannt, I. A systematic review of immersive virtual reality applications for higher education: Design elements, lessons learned, and research agenda. Comput. Educ. 2020, 147, 103778. [CrossRef]

33. Lee, E.A.-L.; Wong, K.W.; Fung, C.C. How does desktop virtual reality enhance learning outcomes? A structural equation modeling approach. Comput. Educ. 2010, 55, 1424-1442.

34. Davis, F.D. User acceptance of information technology; system characteristics, user perceptions and behavioral impacts. Int. J. Manag. Mach. Stud. 1993, 475-487. [CrossRef]

35. Sepasgozar, S.M.E.; Bernold, L.E. A Technology pre-adoption model for construction. In Proceedings of the 37th Annual Conference of Australasian University Building Educators Association (AUBEA), Sydney, Australia, 30 September-3 October 2008.

36. McNamara, A.J.; Sepasgozar, S.M. Developing a theoretical framework for intelligent contract acceptance. Constr. Innov. 2020. [CrossRef]

37. Garone, A.; Pynoo, B.; Tondeur, J.; Cocquyt, C.; Vanslambrouck, S.; Bruggeman, B.; Struyven, K. Clustering university teaching staff through UTAUT: Implications for the acceptance of a new learning management system. Br. J. Educ. Technol. 2019, 50, 2466-2483. [CrossRef]

38. Revythi, A.; Tselios, N. Extension of Technology Acceptance Model by using System Usability Scale to assess behavioral intention to use e-learning. Educ. Inf. Technol. 2019, 24, 2341-2355. [CrossRef]

39. Nakarada-Kordic, I.; Reay, S.; Bennett, G.; Kruse, J.; Lydon, A.-M.; Sim, J. Can virtual reality simulation prepare patients for an MRI experience? Radiography 2019. [CrossRef]

40. Kim, H.K.; Park, J.; Choi, Y.; Choe, M. Virtual reality sickness questionnaire (VRSQ): Motion sickness measurement index in a virtual reality environment. Appl. Ergon. 2018, 69, 66-73. [CrossRef]

41. Bergmann, J.; Sams, A. Flipped learning: Gateway to Student Engagement; International Society for Technology in Education: Washington, DC, USA, 2014.

42. Balan, P.; Clark, M.; Restall, G. Preparing students for Flipped or Team-Based Learning methods. Educ. Train. 2015, 57, 639-657. [CrossRef]

43. Bliemel, M.J. Lessons learned from an inside-out flip in entrepreneurship education. Small Enterp. Res. 2014, 21, 117-128. [CrossRef] 
44. Goldfinch, J.; Raeside, R. Development of a peer assessment technique for obtaining individual marks on a group project. Assess. Eval. High. Educ. 1990, 15, 210-231. [CrossRef]

45. Lejk, M.; Wyvill, M. Peer assessment of contributions to a group project: A comparison of holistic and category-based approaches. Assess. Eval. High. Educ. 2001, 26, 61-72. [CrossRef]

46. Brooks, C.M.; Ammons, J.L. Free riding in group projects and the effects of timing, frequency, and specificity of criteria in peer assessments. J. Educ. Bus. 2003, 78, 268-272. [CrossRef]

47. Juhaňák, L.; Zounek, J.; Rohlíková, L. Using process mining to analyze students' quiz-taking behavior patterns in a learning management system. Comput. Hum. Behav. 2019, 92, 496-506. [CrossRef]

48. Biasutti, M.; EL-Deghaidy, H. Interdisciplinary project-based learning: An online wiki experience in teacher education. Technol. Pedagog. Educ. 2015, 24, 339-355. [CrossRef]

49. Elmahadi, I.; Osman, I. A study of the Sudanese students' use of collaborative tools within moodle learning management system. In Proceedings of the IST-Africa Conference and Exhibition (IST-Africa), Nairobi, Kenya, 29-31 May 2013; pp. 1-8.

50. Sonego, A.H.S.; do Amaral, É.M.H.; Nunes, F.B.; Voss, G.B. Use of Moodle as a tool for collaborative learning: A study focused on wiki. IEEE Rev. Iberoam. Tecnol. Aprendiz. 2014, 9, 17-21. [CrossRef]

51. Gutiérrez-Braojos, C.; Montejo-Gamez, J.; Marin-Jimenez, A.; Campaña, J. Hybrid learning environment: Collaborative or competitive learning? Virtual Real. 2019, 23, 411-423. [CrossRef]

52. Cooper, G.; Park, H.; Nasr, Z.; Thong, L.; Johnson, R. Using virtual reality in the classroom: Preservice teachers' perceptions of its use as a teaching and learning tool. Educ. Media Int. 2019, 56, 1-13. [CrossRef]

53. Monahan, T.; McArdle, G.; Bertolotto, M. Virtual reality for collaborative e-learning. Comput. Educ. 2008, 50, 1339-1353. [CrossRef]

54. Zheng, L.; Zhang, X.; Gyasi, J.F. A literature review of features and trends of technology-supported collaborative learning in informal learning settings from 2007 to 2018. J. Comput. Educ. 2019, 6, 529-561. [CrossRef]

55. Dominic, M.; Francis, S.; Pilomenraj, A. E-learning in web 3.0. Int. J. Mod. Educ. Comput. Sci. 2014, 6, 8. [CrossRef]

56. Männistö, M.; Mikkonen, K.; Kuivila, H.M.; Virtanen, M.; Kyngäs, H.; Kääriäinen, M. Digital collaborative learning in nursing education: A systematic review. Scand. J. Caring Sci. 2019. [CrossRef] [PubMed]

57. Halavais, A. Computer-Supported Collaborative Learning. Int. Encycl. Commun. Theory Philos. 2016, 1-5. [CrossRef]

58. Blau, I.; Shamir-Inbal, T.; Avdiel, O. How does the pedagogical design of a technology-enhanced collaborative academic course promote digital literacies, self-regulation, and perceived learning of students? Internet High. Educ. 2020, 45, 100722. [CrossRef]

59. Sepasgozar, S.M.; Davis, S.; Loosemore, M.; Bernold, L. An investigation of modern building equipment technology adoption in the Australian construction industry. Eng. Constr. Archit. Manag. 2018. [CrossRef]

60. Sepasgozar, S.M.; Davis, S.R.; Li, H.; Luo, X. Modeling the Implementation Process for New Construction Technologies: Thematic Analysis Based on Australian and US Practices. J. Manag. Eng. 2018, 34, 05018005. [CrossRef]

61. Sepasgozar, S.M.; Davis, S. Construction Technology Adoption Cube: An Investigation on Process, Factors, Barriers, Drivers and Decision Makers Using NVivo and AHP Analysis. Buildings 2018, 8, 74. [CrossRef]

62. Mak, T.M.; Iris, K.; Wang, L.; Hsu, S.-C.; Tsang, D.C.; Li, C.; Yeung, T.L.; Zhang, R.; Poon, C.S. Extended theory of planned behaviour for promoting construction waste recycling in Hong Kong. Waste Manag. 2019, 83, 161-170. [CrossRef]

63. Horton, J.; Macve, R.; Struyven, G. Qualitative research: Experiences in using semi-structured interviews. In The Real Life Guide to Accounting Research; Elsevier: Amsterdam, The Netherlands, 2004; pp. 339-357.

64. Sepasgozar, S.M.E.; Loosemore, M.; Davis, S.R. Conceptualising information and equipment technology adoption in construction A critical review of existing research. Eng. Constr. Archit. Manag. 2016, 23, 158-176. [CrossRef]

65. Rogers, E.M. Diffusion of Innovations, 4th ed.; Free Press: New York, NY, USA, 1995.

66. Sepasgozar, S. Footing Construction Process [Immersive Environment for Teaching]. YouTube: Sydney. 2020. Available online: https://www.youtube.com/watch?v=aZFGxmVAbFM (accessed on 1 July 2020).

67. Sepasgozar, S. Site Layout [Immersive Teaching] Sydney. 2020. Available online: https://www.youtube.com/ watch?v=5qJnLjjr2jY (accessed on 1 July 2020). 
68. Shirowzhan, S.; Tan, W.; Sepasgozar, S.M. Digital Twin and CyberGIS for Improving Connectivity and Measuring the Impact of Infrastructure Construction Planning in Smart Cities; Multidisciplinary Digital Publishing Institute: Basel, Switzerland, 2020.

69. Shirowzhan, S.; Sepasgozar, S.M.E.; Li, H.; Trinder, J. Spatial compactness metrics and Constrained Voxel Automata development for analyzing 3D densification and applying to point clouds: A synthetic review. Autom. Constr. 2018, 96, 236-249. [CrossRef]

70. Shirowzhan, S.; Sepasgozar, S.M. Spatial analysis using temporal point clouds in advanced GIS: Methods for ground elevation extraction in slant areas and building classifications. ISPRS Int. J. Geo Inf. 2019, 8, 120. [CrossRef]

71. Venkatesh, V.; Morris, M.G.; Davis, G.B.; Davis, F.D. User acceptance of information technology: Toward a unified view. MIS Q. Manag. Inf. Syst. 2003, 27, 425-478. [CrossRef]

72. Lee, J.; Kim, J.; Ahn, J.; Woo, W. Context-aware risk management for architectural heritage using historic building information modeling and virtual reality. J. Cult. Herit. 2019, 38, 242-252. [CrossRef]

73. Shi, Y.; Du, J.; Ahn, C.R.; Ragan, E. Impact assessment of reinforced learning methods on construction workers' fall risk behavior using virtual reality. Autom. Constr. 2019, 104, 197-214. [CrossRef]

74. Jantakoon, T.; Wannapiroon, P.; Nilsook, P. Virtual Immersive Learning Environments (VILEs) Based on Digital Storytelling to Enhance Deeper Learning for Undergraduate Students. High. Educ. Stud. 2019, 9, 144-150. [CrossRef]

75. Templeton, C.; Kessinger, M.W. Virtual Reality: Learning by Seeing in 3D. In Handbook of Research on Software for Gifted and Talented School Activities in K-12 Classrooms; IGI Global: Hershey, PA, USA, 2020; pp. $94-119$.

76. Violante, M.G.; Vezzetti, E.; Piazzolla, P. Interactive virtual technologies in engineering education: Why not $360^{\circ}$ videos? Int. J. Interact. Des. Manuf. (Ijidem) 2019, 13, 729-742. [CrossRef]

77. Raghavan, R.; Rao, P. Accenture Extended Reality (XR): Immersive Learning for the Future Workforce; IEEE: New York, NY, USA, 2018.

78. Scherer, R.; Siddiq, F.; Tondeur, J. The technology acceptance model (TAM): A meta-analytic structural equation modeling approach to explaining teachers' adoption of digital technology in education. Comput. Educ. 2019, 128, 13-35. [CrossRef]

79. Venkatesh, V. Determinants of Perceived Ease of Use: Integrating Control, Intrinsic Motivation, and Emotion into the Technology Acceptance Model. Inf. Syst. Res. 2000, 11, 342-365. [CrossRef]

80. Sepasgozar, S.M.; Hawken, S.; Sargolzaei, S.; Foroozanfa, M. Implementing citizen centric technology in developing smart cities: A model for predicting the acceptance of urban technologies. Technol. Forecast. Soc. Chang. 2019, 142, 105-116. [CrossRef]

81. Sepasgozar, S.; Shirowzhan, S.; Wang, C.C. A Scanner Technology Acceptance Model for Construction Projects. Procedia Eng. 2017, 1237-1246. [CrossRef]

82. Wittrock, M.C. Generative Processes of Comprehension. Educ. Psychol. 1989, 24, 345-376. [CrossRef]

83. Usoh, M.; Catena, E.; Arman, S.; Slater, M. Using presence questionnaires in reality. Presence Teleoper. Virtual Environ. 2000, 9, 497-503. [CrossRef]

84. Youngblut, C.; Huie, O. The relationship between presence and performance in virtual environments: Results of a VERTS study. In Proceedings of the IEEE Virtual Reality, Los Angeles, CA, USA, 22-26 March 2003; pp. 277-278.

85. Pallavicini, F.; Cipresso, P.; Raspelli, S.; Grassi, A.; Serino, S.; Vigna, C.; Triberti, S.; Villamira, M.; Gaggioli, A.; Riva, G. Is virtual reality always an effective stressors for exposure treatments? Some insights from a controlled trial. BMC Psychiatry 2013, 13, 52. [CrossRef]

86. Witmer, B.G.; Jerome, C.J.; Singer, M.J. The factor structure of the presence questionnaire. Presence Teleoper. Virtual Environ. 2005, 14, 298-312. [CrossRef]

87. Sepasgozar, S.M.; Wang, C.; Shirowzhan, S. Challenges and Opportunities for Implementation of Laser Scanners in Building Construction. In Proceedings of the 33rd International Symposium on Automation and Robotics in Construction (ISARC 2016), Auburn, Alabama, USA, 18 July 2016; pp. 742-751.

88. Shirowzhan, S.; Sepasgozar, S.; Liu, C. Monitoring physical progress of indoor buildings using mobile and terrestrial point clouds. In Proceedings of the Construction Research Congress, New Orleans, Louisiana, USA, 16 May 2018.

89. Shirowzhan, S.; Lim, S.; Trinder, J. Enhanced autocorrelation-based algorithms for filtering airborne lidar data over urban areas. J. Surv. Eng. 2016, 142, 04015008. [CrossRef] 
90. Shirowzhan, S.; Trinder, J. Building classification from lidar data for spatio-temporal assessment of 3D urban developments. Procedia Eng. 2017, 180, 1453-1461. [CrossRef]

91. Shirowzhan, S.; Lim, S.; Trinder, J.; Li, H.; Sepasgozar, S.M.E. Data mining for recognition of spatial distribution patterns of building heights using airborne lidar data. Adv. Eng. Inform. 2020, 43, 101033. [CrossRef]

92. Shirowzhan, S.; Sepasgozar, S.M.; Li, H.; Trinder, J.; Tang, P. Comparative analysis of machine learning and point-based algorithms for detecting 3D changes in buildings over time using bi-temporal lidar data. Autom. Constr. 2019, 105, 102841. [CrossRef]

93. Zhong, B.; Xing, X.; Luo, H.; Zhou, Q.; Li, H.; Rose, T.; Fang, W. Deep learning-based extraction of construction procedural constraints from construction regulations. Adv. Eng. Inform. 2020, 43, 101003. [CrossRef]

94. Shirowzhan, S.; Sepasgozar, S.M.E.; Zaini, I.; Wang, C. An integrated GIS and Wi-Fi based locating system for improving construction labor communications. In Proceedings of the 34th International Symposium on Automation and Robotics in Construction (ISARC 2017), Taipei, Taiwan, 1 January 2017; pp. 1052-1059.

95. Sepasgozar, S.M.; Forsythe, P.; Shirowzhan, S.; Norzahari, F. Scanners And photography: A combined framework. In Proceedings of the 40th Australasian Universities Building Education Association (AUBEA) 2016 Conference, Cairns, Australia, 8 July 2016; pp. 819-828.

96. Sepasgozar, S.M.; Forsythe, P.; Shirowzhan, S. Evaluation of terrestrial and mobile scanner technologies for part-built information modeling. J. Constr. Eng. Manag. 2018, 144, 04018110. [CrossRef]

97. Sepasgozar, S.; Lim, S.; Shirowzhan, S.; Kim, Y.; Nadoushani, Z.M. Utilisation of a New Terrestrial Scanner for Reconstruction of As-built Models: A Comparative Study. In Proceedings of the International Symposium on Automation and Robotics in Construction, Oulu, Finland, 15-18 June 2015.

98. Tahmasebinia, F.; Niemelä, M.; Ebrahimzadeh Sepasgozar, S.; Lai, T.; Su, W.; Reddy, K.; Shirowzhan, S.; Sepasgozar, S.; Marroquin, F. Three-Dimensional Printing Using Recycled High-Density Polyethylene: Technological Challenges and Future Directions for Construction. Buildings 2018, 8, 165. [CrossRef]

99. Shirowzhan, S.; Sepasgozar, S.M.E.; Edwards, D.J.; Li, H.; Wang, C. BIM compatibility and its differentiation with interoperability challenges as an innovation factor. Autom. Constr. 2020, 112, 103086. [CrossRef]

100. Zhao, P.A.; Wang, C.C. A comparison of using traditional cost estimating software and BIM for construction cost control. In Proceedings of the ICCREM 2014: Smart Construction and Management in the Context of New Technology, Kunming, China, 27-28 September 2014; pp. 256-264.

101. Sami Ur Rehman, M.; Thaheem, M.J.; Nasir, A.R.; Khan, K.I.A. Project schedule risk management through building information modelling. Int. J. Constr. Manag. 2020, 1-11. [CrossRef]

102. Hosseini, M.R.; Chileshe, N.; Zuo, J.; Baroudi, B. Adopting global virtual engineering teams in AEC Projects. Constr. Innov. 2015. [CrossRef]

103. Boje, C.; Guerriero, A.; Kubicki, S.; Rezgui, Y. Towards a semantic Construction Digital Twin: Directions for future research. Autom. Constr. 2020, 114, 103179. [CrossRef]

104. Ruge, G.; McCormack, C. Building and construction students' skills development for employability-reframing assessment for learning in discipline-specific contexts. Archit. Eng. Des. Manag. 2017, 13, 365-383. [CrossRef]

105. Ruge, G.; Tokede, O.; Tivendale, L. Implementing constructive alignment in higher education-Cross -institutional perspectives from Australia. High. Educ. Res. Dev. 2019, 38, 833-848. [CrossRef]

106. Da Motta Gaspar, J.A.; Ruschel, R.C.; Monteiro, E.Z. Integrated and collaborative architectural design: 10 years of experience teaching BIM. In Advances in Informatics and Computing in Civil and Construction Engineering; Springer: Berlin, Germany, 2019; pp. 865-872.

107. Pollalis, C.; Minor, E.J.; Westendorf, L.; Fahnbulleh, W.; Virgilio, I.; Kun, A.L.; Shaer, O. Evaluating learning with tangible and virtual representations of archaeological artifacts. In Proceedings of the Twelfth International Conference on Tangible, Embedded, and Embodied Interaction, Stockholm, Sweden, 18-21 March 2018; pp. 626-637.

(C) 2020 by the author. Licensee MDPI, Basel, Switzerland. This article is an open access article distributed under the terms and conditions of the Creative Commons Attribution (CC BY) license (http://creativecommons.org/licenses/by/4.0/). 